Document de Recherche du Laboratoire d'Économie d'Orléans

Working Paper Series, Economic Research Department of the University of Orléans (LEO), France

DR LEO 2020-05

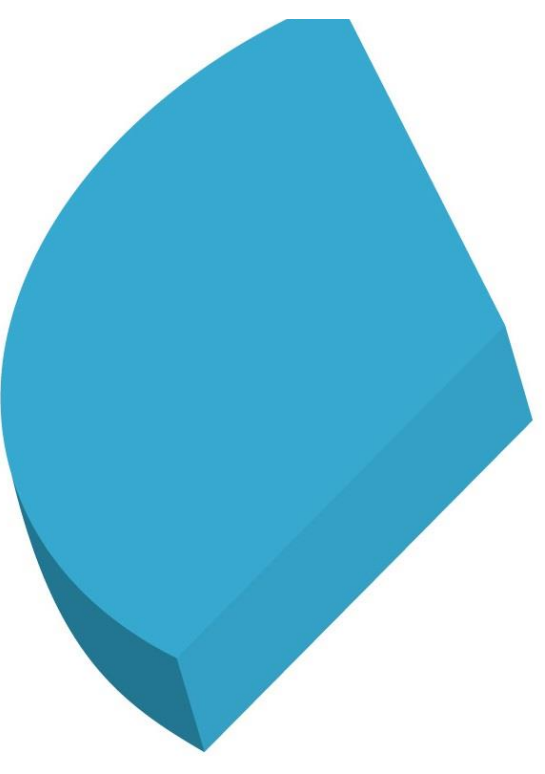

\title{
When could macroprudential and monetary policies be in conflict?
}

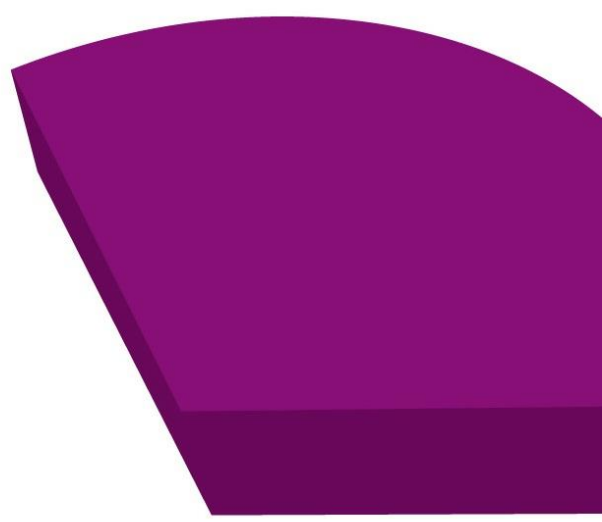

José D. GARCIA-REVELO

Grégory LEVIEUGE

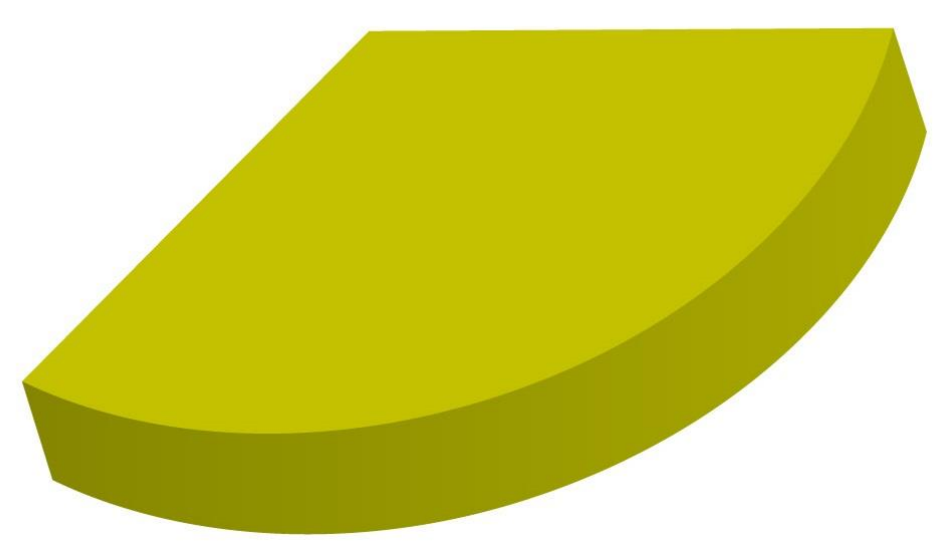

Mise en ligne / Online : 22/05/2020 


\title{
When could macroprudential and monetary policies be in conflict?
}

\author{
Jose D. Garcia Revelo*
}

Grégory Levieuge ${ }^{\dagger}$

May 2020

\begin{abstract}
This paper aims to provide a comprehensive analysis of the potential conflicts between macroprudential and monetary policies within a DGSE model with financial frictions. The identification of conflicts is conditional on different types of shocks, different policy instruments, and different policy objectives (variance of key variables, probability of a crisis, growth-at-risk). We first find that conflicts are not systematic but are fairly frequent, especially in the case of supply-side and widespread shocks such as technology and bank capital shocks. Second, monetary policy and countercyclical capital requirements generate conflicts in many circumstances. By affecting interest rates, they both "get in all the cracks", albeit with their respective targets generally moving in opposite directions. Nonetheless, monetary policy could reduce its adverse financial side effects by responding strongly to the output gap. Third, loan-to-value caps, as sector-specific instruments, cause few conflicts. Thus, they can be easily implemented without concerns about generating potential spillovers, whereas smooth coordination is required between the implementation of capital requirements and of monetary policy.
\end{abstract}

JEL Codes: E44, E58, E61

Keywords: Macroprudential policy, Loan-to-value, Countercyclical buffer, Monetary policy, Conflicts, DSGE model.

\footnotetext{
* Univ. Orléans, CNRS, LEO, FRE 2014, F-45067, Orléans, France.

E-mail address: josedavidgarciarevelo@gmail.com.

${ }^{\dagger}$ Banque de France, DGEI-DEMFI-RECFIN, 31, rue Croix des Petits Champs, 75049 Paris Cedex 01, France, and Univ. Orléans, CNRS, LEO, FRE 2014, F-45067, Orléans, France.

E-mail address: gregory.levieuge@banque-france.fr.

We thank Fabrice Collard, Cristina Jude, Robin Lumsdaine, Julien Matheron, Raoul Minetti, Paolo Gelain and JeanGuillaume Sahuc for their very helpful comments and suggestions at different stages of this research project. The views expressed in this paper are those of the authors and do not necessarily reflect the views of the Banque de France or the Eurosystem.
} 


\section{Introduction}

Macroprudential policy has become a full-fledged tool of economic policy in recent years, as shown by the prompt relaxation of financial requirements in response to the COVID-19 crisis in many countries. This trend emerged in the wake of the global financial crisis, when many countries started implementing macroprudential policies to tame lending practices and build buffers for greater resilience. Such measures are supported by both theoretical foundations (Bianchi and Mendoza, 2018; Mendicino et al., 2018; Farhi and Werning, 2016) and empirical evidence of their effectiveness (Altunbas et al., 2018; Cerutti et al., 2017). Nevertheless, these new arrangements raise the question of potential conflicts arising between macroprudential and monetary policies. As represented by Figure 1, macroprudential measures may have side effects in terms of inflation and output stabilization, which are the main objectives of monetary policy. Similarly, monetary policy can prevent macroprudential policy from achieving its objectives of ensuring financial stability and resilience, which in practice often involves dampening the credit cycle. However, literature on these conflicts is still scarce. Under which circumstances are they likely to occur?

Figure 1: Potential conflicts between macroprudential and monetary policy objectives

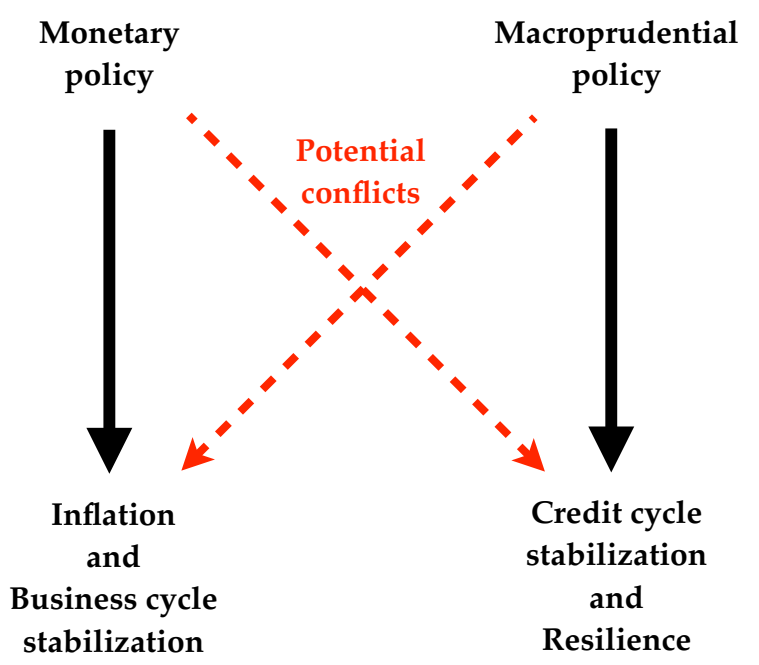

The aim of this paper is to provide a comprehensive analysis of the conditions under which such policy conflicts may arise. These conditions are evaluated based on (i) different types of shocks (real vs financial, demand vs supply-side, global vs sectoral), (ii) different policy instruments (interest rate, countercyclical loan-to-value limits and capital requirements) and (iii) different policy objectives (volatility of the output gap, inflation, and the credit gap, but also the probability of crisis and growth-at-risk).

Our theoretical investigation builds on Gerali et al. (2010). The are several arguments for the appropriateness of this framework for our research question. First, it is a realistic model, with nominal and real rigidities, estimated on euro area data. Second, the model embeds a banking sector that provides intermediation between patient households, on the one hand, and firms and impatient households, on the other hand. Third, it features financial frictions stemming from collateral constraints à la Iacoviello (2005). Such constraints may generate a debt-deflation mechanism that makes the financial sector amplify the severity of shocks. Last, the banking sector in the model duly reproduces the sluggish adjustment of retail interest rates. This is important for assessing the effects of monetary policy, as well as those of capital requirements, which also impact interest rates, as we will see. 
In this model, we introduce three macroprudential rules pursuing two common and representative regulations objectives, i.e., building buffers and taming lending practices. In line with the Basel III framework $^{1}$ and the recommendations of the European Systemic Risk Board (ESRB/2014/1) ${ }^{2}$, the first policy is a regulatory countercyclical capital buffer $(\mathrm{CCyB})$ that supplements, conditionally on the context, the regulatory fixed capital that banks are required to hold. This lender-based instrument has been increasingly used by regulators in recent years. It consists of building and releasing buffers to safeguard the banking sector's resilience and ability to function effectively under any circumstances. For example, the vast majority of countries with a positive CCyB before year-end 2019 rapidly cut them in March 2020 to deal with the adverse economic effects of the COVID-19 pandemic. ${ }^{3}$ Macroprudential authorities have explicitly advised banks to use the additional space created by relaxing the buffer to address increases in expected losses and support credit. In addition, we incorporate two state-dependent loan-to-value (LTV) caps, for households and for firms, into the model. LTV limits are the most commonly used borrower-based measures. They aim to dampen the credit cycle by reducing procyclical feedback between asset prices and credit. We assume that these three macroprudential instruments react to excess credit, in line with regulatory recommendations. Finally, we model monetary policy as a standard interest rate rule.

Next, we follow a descriptive approach that is agnostic regarding policymakers' preferences. The aim of our analysis is not to determine optimal monetary and macroprudential policies or the optimal policy mix. Instead, we conduct an upstream investigation that seeks to identify cases in which conflicts may spontaneously arise. To this end, we separately focus on several variables that are likely to enter policymakers' objective functions (inflation, output gap, credit-to-GDP gap) without imposing policy preferences. ${ }^{4}$ We examine the sensitivity of each of these variables to the reaction parameters of the macroprudential and monetary policy rules. This approach is better suited to identifying the source of policy conflicts in a shock-by-shock analysis. More precisely, a conflict is identified when increasing the strength of macroprudential (resp., monetary) policy rules leads to higher inflation volatility and a larger output gap (resp., credit-to-GDP gap) in the contexts depicted by four alternative shocks. We also consider extreme vulnerabilities as alternative objectives of policymakers by studying the effects of monetary policy on the likelihood of a financial crisis as well as the effects of macroprudential policies on the downside risk of GDP growth (growth-at-risk).

We find that conflicts between macroprudential and monetary policies are fairly frequent but not systematic. They are especially likely to arise in cases of technological and bank capital shocks. These two supply-side shocks have a more widespread impact on the economy than that of sector-specific shocks such as housing shocks. Regarding policy instruments, it appears that $\mathrm{CCyB}$ and monetary policy generate conflicts in many cases. While they both "get in all the cracks" by widely impacting the economy through adjustments to retail rates, their main respective targets - i.e., inflation and the credit gap - often move in opposite directions. Nonetheless, it appears that the stronger the reaction of monetary policy to the output gap, the less frequent are conflicts stemming from monetary policy, as credit and output gaps are often positively correlated. In contrast, LTV caps, as sector-specific instruments, cause few conflicts. Moreover, even when LTV caps are found to increase real volatility,

\footnotetext{
${ }^{1}$ https://www.bis.org/bcbs/ccyb/index.htm.

${ }^{2}$ See also the transposition of the Basel III standards on bank capital adequacy into the Capital Requirements Directive (Art. 136 CRD IV) of European Union law (2013/36/EU).

${ }^{3}$ In the euro area, France, Germany, Ireland and Lithuania followed this recommendation emanating from the ECB.

${ }^{4}$ Note that the literature is unclear in this respect. The welfare-based loss function that is derived from the representative agent's utility function is usually split into two parts that are assigned on an ad hoc basis to the central bank and the macroprudential authority (See, e.g., Rubio and Yao, 2020; De Paoli and Paustian, 2017).
} 
they eventually reduce downside risks to GDP. These results thus suggest that LTV limits can be easily implemented without concerns about potential spillovers. In contrast, the implementation of $\mathrm{CCyB}$ and of monetary policy requires smooth coordination.

Our paper contributes to the emerging literature on macroprudential-monetary policy interactions. ${ }^{5}$ This study is close to Angelini et al. (2014), also built on Gerali et al. (2010) but with different motivations and a different approach. Nonetheless, at the margins of our analysis, we employ their optimizing framework to illustrate the conflicts that we find in terms of policy trade-offs. This work is also close to that of Silvo (2019), who investigates policy interactions but by applying a different approach (Ramsey-optimal policy) in a model with different financial frictions (based on Holmstrom and Tirole, 1997). However, we find quite similar results in the case of supply-side shocks. Aikman et al. (2019) also deal with this issue in a very different two-period model incorporating the possibility of a financial crisis. We retain the way they compute the probability of a crisis. Our analysis can also be linked to the research on the financial side effects of monetary policy, despite the fact that such negative financial externalities do not precisely rely on the so-called risk-taking channel in our model. Finally, by examining potential conflicts, we also contribute to the literature on coordination of monetary and macroprudential policies (Bodenstein et al., 2019; Collard et al., 2017; Gelain and Ilbas, 2017; De Paoli and Paustian, 2017; Rubio and Carrasco-Gallego, 2014).

Generally, we propose an assessment of conflicts that is more global than what can be found in the existing literature. We first go a step further than other analyses by considering several countercyclical macroprudential rules, reacting to model-consistent credit-to-GDP gaps. In addition, we cover a wider set of shocks. Third, we depart from the usual ad hoc split of the welfare-based loss function by considering a large range of plausible calibrations for the policy rules. We also consider a broader set of potential objectives, from the usual volatilities of key variables to more extreme vulnerabilities such as the probability of a crisis or growth-at-risk. ${ }^{6}$ Finally, the originality of our contribution lies in the new results that we obtain. We identify the instruments and circumstances that are most prone to conflicts, and we provide explanations based on the transmission channel of these different policy tools. This overall assessment may enlighten monetary and prudential authorities on the potential spillovers of their policies and the need for coordination.

The remainder of this paper is structured as follows. Section 2 reviews the main theoretical and empirical contributions of the related literature. Section 3 presents the DSGE model that we use. Section 4 shows the response of our model to four shocks chosen to cover a set of interesting contexts. Section 5 is devoted to the identification of conflicts and the interpretation of their main causes. Section 6 extends the analysis to extreme vulnerabilities. Finally, section 7 concludes.

\section{Literature review}

Macroprudential tools have been progressively implemented for approximately a decade in most developed countries. ${ }^{7}$ This section reviews the justifications for such instruments and the way they are supposed to interact with monetary policy.

First, the implementation of macroprudential policies is supported by theoretical foundations. Gersbach and Rochet (2017) demonstrate how capital requirements improve social welfare by dealing with

\footnotetext{
${ }^{5}$ See details below in the literature review.

${ }^{6}$ Hence, any policymaker can evaluate the (side) effects of his policy by picking out the variables that enter his loss function and assigning to each of them the relative weight corresponding to his preferences.

${ }^{7}$ See, e.g., Alam et al. (2019) and Cerutti et al. (2017) for details on these measures.
} 
the procyclical lending behaviour of banks. This is confirmed by analyses based on DSGE models featuring financial imperfections and constraints. In this vein, Bianchi and Mendoza (2018) show, in a framework embedding a debt-deflation mechanism, that the optimal macroprudential policy increases social welfare by reducing the probability and magnitude of crises. Regarding the measures that we consider in our analysis, the optimality of (countercyclical) capital requirements is demonstrated by Mendicino et al. (2018) and Benes and Kumhof (2015). Countercyclical regulatory LTV ratios are also found to be welfare-improving by Alpanda and Zubairy (2017) and Rubio and Carrasco-Gallego (2014), although the benefits may differ for borrowers and savers (Lambertini et al., 2013). Another branch of the literature provides a foundation for macroprudential tools by demonstrating that they generate Pareto improvements when monetary policy is stuck at the zero lower bound (Rubio and Yao, 2020; Farhi and Werning, 2016; Korinek and Simsek, 2016).

Empirical studies validate these favourable effects. Macroprudential measures have been proven to reduce banking risk through balance-sheet adjustments (Altunbas et al., 2018; Claessens et al., 2013), especially due to the impact on credit growth (Cerutti et al., 2017). Regarding the two macroprudential tools that we consider in our model, De Jonghe et al. (2020) and Vandenbussche et al. (2015) find that capital requirements are effective in lowering credit supply to firms and to households, while Alam et al. (2019) find strong effects of LTV limits on household credit.

However, macroprudential tools can have side effects on the targets of monetary policy, and vice versa. This interaction issue has arisen recently as macroprudential measures have been progressively implemented. Therefore, this literature is still in its infancy and includes only a few studies. ${ }^{8}$ Some of them demonstrate or suggest that macroprudential decisions can conflict with the objectives of monetary policy. The contribution of Angelini et al. (2014) can be appreciated through the lens of the potentially adverse side effects of countercyclical capital requirements. These authors find that the latter are conducive to higher inflation volatility in the case of a bank capital shock and to higher output volatility in the case of a technology shock. Based on a slightly different DSGE model, Silvo (2019) also find that countercyclical capital requirements may work against monetary policy in the case of a technology shock. In a simple two-period model, Aikman et al. (2019) show that reducing the probability of a crisis is costly in terms of output and inflation, at least in the short run. In addition, we can deduce from the literature on the risk-taking channel, which states that policy rates that are "too low for too long" create financial instability ${ }^{9}$, that monetary policy can go against macroprudential objectives.

Empirical evidence on interdependencies is rather mixed. Some studies conclude that there is little interaction between the two types of policies. Aiyara et al. (2016), for example, find that the effect of monetary policy on lending is not significantly affected by simultaneous changes in capital requirements. Others conclude that the two policies are complementary: Gambacorta and Murcia (2020), Garcia Revelo et al. (2020) and Bruno et al. (2017) find that macroprudential tools have a greater effect on credit growth when reinforced by the use of monetary policy. However, according to Kim and Mehrotra (2018), this complementarity is challenged at times of low inflation and buoyant credit growth, which implies that macroprudential and monetary policies are working at cross-purposes. Indeed, another part of the literature reveals the existence of conflicts. Richter et al. (2018), for instance, show that a decrease in the LTV ratio reduces output. Fraisse et al. (2020), Juelsrud and Wold (2020) and Gropp et al. (2018) find that capital requirements negatively affect investment, consumption and employment.

\footnotetext{
${ }^{8}$ Note that we exclude from this review papers that concentrate on the "leaning against the wind" strategy, as they focus more on augmented Taylor rules than on macroprudential measures per se.

${ }^{9}$ See Brunnermeier and Sannikov (2014) and Farhi and Tirole (2012), inter alia.
} 
In addition, many studies validate the adverse side effects of monetary policy through the risk-taking channel (See, e.g., Colletaz et al., 2018; Jimenez et al., 2014).

Despite the lack of solid theoretical and empirical evidence on interdependencies between monetary and macroprudential policies, an emerging literature focuses on how to articulate them optimally. In line with the Tinbergen separation principle, Collard et al. (2017) find that it is optimal to assign the goal of financial stability to prudential policy and the goal of macroeconomic stabilization to the interest rate policy. Moreover, optimal interaction would require cutting (raising) interest rates to moderate the contractions (expansions) caused by tightening (easing) of capital requirements. Likewise, Aikman et al. (2019) find that it is optimal to tighten CCyBs in response to a credit boom and to cushion the macroeconomic impact by loosening monetary policy. These required adjustments of the policy rate contrast with the aforementioned literature that recommends the implementation of macroprudential measures to compensate for the shortcomings and the adverse effects of monetary policy at the ZLB. Nonetheless, at least these two different views agree on the need to coordinate policies. A demonstration of the gains from cooperation is provided by Lazopoulos and Gabriel (2019) and Bodenstein et al. (2019) in different setups.

In contrast, De Paoli and Paustian (2017) demonstrate that a noncooperative setting in which the macroprudential authority acts as a leader can be superior to cooperation. Rubio and Carrasco-Gallego (2014) find that the non-coordination configuration delivers higher social welfare, as each authority focusing on its own objective is more effective in achieving it. According to Gelain and Ilbas (2017), the relative gains of coordination may depend on the importance given to the output gap in the policies' mandates.

We contribute to the scarce theoretical literature on macroprudential-monetary policy conflicts by providing a comprehensive assessment of the conditions under which each policy may spontaneously prevent the other from achieving its objectives. We consider this as a prerequisite to the analysis of optimal coordination. ${ }^{10}$ To this end, we follow a descriptive and agnostic approach. This involves considering more policy tools, more shocks and a broader set of potential objective variables than those that appear in the existing literature. Furthermore, we adopt an original way of identifying conflicts, based on the effects of the strength of monetary (resp., macroprudential) policy response to its targets on the macroprudential (resp., monetary) objectives, shock by shock. Finally, explanations of adverse side effects are based on the transmission channel of the different policy tools. The next section presents the model used for this analysis.

\section{The model}

\subsection{Overview}

Our analysis builds on the model developed by Gerali et al. (2010), which offers both tractability and realism. It embeds the usual nominal and real rigidities as well as financial frictions in an explicit banking sector. In this section, we describe its main features to understand the main mechanisms at stake as well as the effects of macroprudential and monetary policies.

The economy is populated by two groups of households (patient $P$ and impatient $I$ ) of unit mass, who consume final goods, work and accumulate housing (in fixed supply). The discount factor of patient households is higher than that of impatient households. This implies positive financial flows in

\footnotetext{
${ }^{10}$ We do not investigate how coordination should be managed but under which circumstances and why it may be needed.
} 
equilibrium, with patient households as savers and impatient households as net borrowers. The latter face a loan-to-value (LTV) constraint imposed by the macroprudential authority. Households supply their differentiated labour services through unions that set nominal wages. Labour services are finally sold to competitive employment agencies that assemble them into a homogenous labour input and sell it to entrepreneurs.

Entrepreneurs produce homogenous intermediate goods using labour and capital bought from capital-good producers. Entrepreneurs are net borrowers, with the same discount factor as impatient households. They also face an LTV constraint.

The banking sector is made up of monopolistically competitive banks, which set interest rates on deposits and loans to maximize their profits. The amount of loans offered to households and entrepreneurs is financed by deposits and bank capital. The latter comes from retained profits. Banks must comply with a regulatory capital to risk-weighted assets ratio and with a statutory leverage ratio imposed by the macroprudential authorities. This means that bank lending is constrained.

The programmes of the households, entrepreneurs and banks are detailed below, whereas the rest of the model, namely, the union (the source of wage rigidity), retail (the source of price rigidity) and capital goods sectors, is presented in Appendix A. The full set of equations is provided in Appendix B.

\subsection{Households}

The representative household $j$ maximizes its expected utility given by

$$
\mathrm{E}_{0} \sum_{t=0}^{\infty} \beta_{i}^{t}\left[\left(1-a^{i}\right) \log \left(c_{t}^{i}(j)-a^{i} c_{t-1}^{i}\right)+\varepsilon_{t}^{h} \log h_{t}^{i}(j)-\frac{l_{t}^{i}(j)^{1+\phi}}{1+\phi}\right], \text { for } i \in\{P, I\}
$$

where $\mathrm{E}_{t}$ denotes the mathematical expectation operator upon information available at $t, a^{i} \in[0,1]$ denotes the degree of habit formation, and $\phi>0$ is the inverse of the Frisch labour supply elasticity. $c_{t}^{i}(j)$ denotes individual consumption, $c_{t-1}^{i}$ is lagged aggregate consumption, $h_{t}^{i}(j)$ is housing services and $l_{t}^{i}$ represents hours worked. In addition, $\varepsilon_{t}^{h}$ captures exogenous real demand shocks affecting preferences for housing. It can be interpreted as a variation in the availability of resources needed to purchase housing relative to other goods or as other social and institutional changes that shift preferences toward housing (Iacoviello and Neri, 2010). The subjective discount factor for the patient households $(P)$ is higher than that of the impatient $(I)$ ones, i.e., $\beta_{P}>\beta_{I}$.

Patient household $i$ 's period budget constraint is given by

$$
c_{t}^{P}(i)+q_{t}^{h} \Delta h_{t}^{P}(i)+d_{t}^{P}(i) \leq w_{t}^{P} l_{t}^{P}(i)+\left(1+r_{t-1}^{d}\right) d_{t-1}^{P}(i) / \pi_{t}+\tau_{t}^{P}(i) .
$$

Its expenses include consumption, accumulation of housing with $q_{t}^{h}$ designating the real house price, and real deposits in period $t$. Its resources consist of real wage earnings, gross interest income on the last period's deposits, with $\pi_{t} \equiv P_{t} / P_{t-1}$ as gross inflation, and lump-sum transfers $\left(\tau_{t}^{P}\right)$. The latter include labour union membership net fees and dividends from firms and banks (of which patient households are the only owners).

Impatient household $i$ 's period budget constraint is given by

$$
c_{t}^{I}(i)+q_{t}^{h} \Delta h_{t}^{I}(i)+\left(1+r_{t-1}^{b H}\right) b_{t-1}^{I} / \pi_{t} \leq w_{t}^{I} l_{t}^{I}(i)+b_{t}^{I}(i)+\tau_{t}^{I}(i)
$$

where the flow of expenses is partly composed of gross reimbursement of the last period's borrowing 
$b_{t-1}^{I}$, with $r_{t-1}^{b H}$ being the corresponding lending rate. Its resources include new loans, as well as lumpsum transfers $\tau_{t}^{I}(i)$ that are only composed of union membership net fees. In addition, impatient households face a borrowing constraint stating that they cannot borrow more (in terms of repayment amount plus interest) than a given proportion $L T V_{t}^{H}$ of the expected value of their housing:

$$
\left(1+r_{t}^{b H}\right) b_{t}^{I}(i) \leq L T V_{t}^{H} \mathrm{E}_{t}\left[q_{t+1}^{h} h_{t}^{I}(i) \pi_{t+1}\right] \varepsilon_{t}^{m}
$$

where $L T V_{t}^{H}$ is a mandatory time-varying loan-to-value limit on mortgages to households imposed by the macroprudential authority. At the macroeconomic level, this LTV cap determines the amount of credit that banks can provide to impatient households for a given (discounted) value of their housing stock. This policy instrument follows a countercyclical rule that depends on a measure of excess mortgage credit (see details below). As in Iacoviello (2005), $1-L T V_{t}^{H}$ can be interpreted as the proportional cost of collateral repossession for banks in case of default. The value of collateral is subject to a stochastic shock denoted $\varepsilon_{t}^{m}$, which can be interpreted as a non-fundamental shock to housing price expectations, in line with Burlon et al. (2018) and Dupor (2005). Optimistic (pessimistic) expectations on the future price of housing loosen (tighten) the lending constraint. This gives scope for representing a financial demand-side shock.

\subsection{Entrepreneurs}

Entrepreneur $i$ 's utility only depends on her own consumption $c_{t}^{E}(i)$ and on lagged aggregate consumption:

$$
\mathrm{E}_{0} \sum_{t=0}^{\infty} \beta_{E}^{t} \log \left(c_{t}^{E}(i)-a^{E} c_{t-1}^{E}\right)
$$

where $a^{E}$ measures the degree of consumption habits and the discount factor $\beta_{E}$ is assumed to be strictly lower than $\beta_{P}$. Entrepreneur $i$ maximizes her lifetime utility under the budget constraint:

$$
c_{t}^{E}(i)+w_{t}^{P} l_{t}^{E, P}(i)+w_{t}^{I} l_{t}^{E, I}(i)+\left(1+r_{t-1}^{b^{E}}\right) b_{t-1}^{E}(i) / \pi_{t}+q_{t}^{k} k_{t}^{E}(i) \leq \frac{y_{t}^{E}(i)}{x_{t}}+b_{t}^{E}(i)+q_{t}^{k}(1-\delta) k_{t-1}^{E}(i)
$$

where expenses are composed of consumption, labour inputs from patient $l_{t}^{E, P}(i)$ and impatient households $l_{t}^{E, I}(i)$, gross repayment of the last period's borrowing $b_{t-1}^{E}(i)$, with $r_{t-1}^{b E}$ being the corresponding lending rate, and physical capital $k_{t}^{E}$, whose price in terms of consumption is denoted $q_{t}^{k}$. Her resources consist of new loans, non-depreciated physical capital resold to capital producers, with $\delta$ being the depreciation rate of physical capital, and wholesale good $y_{t}^{E}$, which is sold at the inverse relative competitive price $x_{t}=P_{t} / P_{t}^{W}$ and produced according to the following technology:

$$
y_{t}^{E}=\varepsilon_{t}^{a}\left[k_{t-1}^{E}(i)\right]^{\alpha}\left[l_{t}^{E}(i)\right]^{1-\alpha}
$$

where $\varepsilon_{t}^{a}$ is an exogenous process for total factor productivity. The labour of the two types of households is combined as $l_{t}^{E}=\left(l_{t}^{E, P}\right)^{\mu}\left(l_{t}^{E, I}\right)^{1-\mu}$, where $\mu$ measures the labour income share of patient households. Finally, like mortgage borrowers, entrepreneurs are subject to a regulatory borrowing constraint, given by

$$
\left(1+r_{t}^{b E}\right) b_{t}^{E}(i) \leq L T V_{t}^{E} \mathrm{E}_{t}\left((1-\delta) q_{t+1}^{k} \pi_{t+1} k_{t}^{E}(i)\right)
$$

which states that the gross borrowing of entrepreneur $i$ cannot exceed a proportion $L T V_{t}^{E}$ of the expected value of her (depreciated) physical capital. The macroprudential instrument $L T V_{t}^{E}$ is set 
with respect to a countercyclical rule that depends on a measure of firms' excess credit (see details below).

\subsection{The banking sector}

The banking sector is composed of a continuum of banking groups, indexed by $j \in[0,1]$, which carry out their intermediation activities under monopolistic competition. Each group is made up of a wholesale unit (management branch) and two retail branches. The retail loan and deposit branches are in charge of granting loans to impatient households and firms and collecting deposits from patient households, respectively, for the group. The wholesale unit manages the bank's capital position, as the banking group balance sheet is subject to a mandatory capital adequacy and leverage ratios. Deviations from these regulatory ratios imply quadratic costs. In this way, bank capital has a key role in determining supply-side credit and deposit conditions. As banks slowly accumulate capital through retained earnings, policy changes or exogenous shocks to bank capital create a feedback loop between the real and financial sides of the economy.

The retail deposit branch. The retail deposit branch $j$, operating in a monopolistic competition context, collects deposits $d_{t}^{P}(j)$ from households at rates $r_{t}^{d}(j)$ and transfers quantity $D_{t}(j)$ to the management branch, which remunerates these funds at internal rate $R_{t}^{d}(j)$. Each deposit retail unit faces quadratic adjustment costs for changing its deposit rate over time. These adjustment costs, denoted as $\mathcal{A}_{d}\left(r_{t}^{d}(j)\right)$, are parameterized by $\kappa_{d}$ and are supposed to be proportional to the aggregate interest paid on deposits, such as $\mathcal{A}_{d}\left(r_{t}^{d}(j)\right) \equiv \frac{\kappa_{d}}{2}\left(r_{t}^{d}(j) / r_{t-1}^{d}(j)-1\right)^{2} r_{t}^{d} d_{t}$, where $d_{t}$ represents aggregate deposits in the economy and $r_{t}^{d}=\left[\int_{o}^{1} r_{t}^{d}(j)^{1-\varepsilon^{d}} d j\right]^{\frac{1}{1-\varepsilon d}}$ is the deposit rate, with $\varepsilon^{d}<-1$ representing the elasticity of demand for deposits. Then, the objective of the retail deposit branch $j$ is to solve

$$
\max _{\left\{r_{t}^{d}(j)\right\}} \mathrm{E}_{0} \sum_{t=0}^{\infty} \Lambda_{0, t}^{P}\left[R_{t}^{d}(j) D_{t}(j)-r_{t}^{d}(j) d_{t}^{P}(j)-\mathcal{A}_{d}\left(r_{t}^{d}(j)\right)\right],
$$

subject to a Dixit-Stiglitz deposit demand curve $d_{t}^{P}(j)=\left(r_{t}^{d}(j) / r_{t}^{d}\right)^{-\varepsilon^{d}} d_{t}$. The first-order condition of this programme defines the way the retail deposit branch optimally sets the retail deposit rate with respect to the adjustment costs, the policy rate and a markdown over the wholesale deposit rate, denoted $\varepsilon^{d} /\left(\varepsilon^{d}-1\right)$, as indicated in eq. B38 in Appendix B.

The retail loan branch. Retail loan branches operate under monopolistic competition. They obtain wholesale loans $B_{t}^{s}(j)$, in real terms, at rates $R_{t}^{b s}(j)$, from the management branch, which pre-allocates wholesale funds for mortgage $(s=H)$ and corporate lending $(s=E)$, given regulatory constraints on the balance sheet. Then, retail loan branches resell these funds to households and entrepreneurs at lending rates $r_{t}^{b H}(j)$ and $r_{t}^{b E}(j)$, respectively, after differentiating them at no cost but facing quadratic adjustment costs for changing them. These costs are parameterized by $\kappa_{b H}$ and $\kappa_{b E}$ and are proportional to aggregate returns on loans. They are denoted $\mathcal{A}_{b s}\left(r_{t}^{b s}(j)\right) \equiv \frac{\kappa_{b s}}{2}\left(r_{t}^{b s}(j) / r_{t-1}^{b s}(j)-1\right)^{2} r_{t}^{b s} b_{t}^{s}$, for $s \in\{H, E\}$, with $r_{t}^{b s}=\left[\int_{o}^{1} r_{t}^{b s}(j)^{1-\varepsilon^{b s}} d j\right]^{\frac{1}{1-\varepsilon^{b s}}}$ and with $b_{t}^{s}$ representing aggregate loans in the economy. The objective of the retail loan branch $j$ is to solve

$$
\max _{\left\{r_{t}^{b H}(j), r_{t}^{b E}(j)\right\}} \mathrm{E}_{0} \sum_{t=0}^{\infty} \Lambda_{0, t}^{P}\left[\sum_{s=H, E}\left(r_{t}^{b s}(j) b_{t}^{s}(j)-\mathcal{A}_{b s}\left(r_{t}^{b s}(j)\right)\right)-\sum_{s=H, E} R_{t}^{b s}(j) B_{t}^{s}(j)\right],
$$


subject to Dixit-Stiglitz loan demand curves $b_{t}^{s}(j)=\left(r_{t}^{b s}(j) / r_{t}^{b s}\right)^{-\varepsilon^{b s}} b_{t}^{s}$. Units of loan contracts, bought by households and entrepreneurs, are a composite constant elasticity of substitution basket of differentiated financial products, with elasticity terms equal to $\varepsilon^{b H}>1$ and $\varepsilon^{b E}>1$, respectively. The first-order conditions give the dynamics of the lending rates $r_{t}^{b s}$ with respect to both their past and expected values and to a markup $\left(\varepsilon^{b s} /\left(\varepsilon^{b s}-1\right)\right)$ over the wholesale lending rate, as given by eq. B39 in Appendix B.

The management branch. The management branch is perfectly competitive. It combines bank capital $\left(K_{t}^{b}\right)$ with retail deposits $D_{t}(j)$ on the liability side and total wholesale funds $B_{t}(j)$ to the retail loan branch, with $B_{t}(j)=B_{t}^{H}(j)+B_{t}^{E}(j)$, on the asset side. This branch manages the capital position of the group. Following the Basel III regulation, each bank is supposed to meet capital adequacy ratio (CAR) requirements. More precisely, banks' capital to risk-weighted assets ratio must be equal to $v_{t}$, a contingent mandatory level set by the macroprudential authority (see details below). Differences in the risk weights for households and firms explain the differences in wholesale allocations $B^{H}(j)$ and $B^{E}(j)$ towards retail branches. The management activity entails quadratic adjustment costs whenever the actual CAR deviates from the required level. ${ }^{11}$ These costs, proportional to outstanding bank capital, are denoted $\mathcal{D}_{t}^{v}\left(K_{t}^{b}(j)\right)$. They are parameterized by $\kappa_{\text {car }}$ and defined by

$$
\mathcal{D}_{t}^{v}\left(K_{t}^{b}(j)\right) \equiv \frac{\kappa_{c a r}}{2}\left(\frac{K_{t}^{b}(j)}{\omega_{t}^{H} B_{t}^{H}(j)+\omega_{t}^{E} B_{t}^{E}(j)}-v_{t}\right)^{2} K_{t}^{b}(j),
$$

with $\omega_{t}^{E}$ and $\omega_{t}^{H}$ being the risk weights relative to entrepreneurs and household loans, respectively. ${ }^{12}$ Following Angelini et al. (2014), these weights are procyclical, decreasing (increasing) when annual output growth $\left(Y_{t}-Y_{t-4}\right)$ increases (decreases):

$$
\omega_{t}^{s}=\left(1-\rho_{s}\right) \omega^{s}+\left(1-\rho_{s}\right) \chi_{s}\left(Y_{t}-Y_{t-4}\right)+\rho_{s} \omega_{t-1}^{s} \text { with } s \in\{H, E\} \quad \text { and } \quad \chi_{s}<0,
$$

where $\chi_{s}$ is the sensitivity of risk weights to the business cycle, $\rho_{s}$ is the parameter of persistence, and $\omega^{s}$ (without time subscript) is the steady-state value of the corresponding weight.

For the sake of realism, we also include requirements for the leverage ratio of banks. Any deviation from the regulatory level (lev) implies a quadratic cost parameterized by $\kappa_{l e v}$, proportional to outstanding bank capital and denoted $\mathcal{D}_{t}^{l e v}\left(K_{t}^{b}(j)\right)$. Details on the leverage ratio and its link with the CAR are provided in Appendix C.

Bank capital is accumulated out of retained earnings, following

$$
\pi_{t} K_{t}^{b}(j)=\left(1-\delta^{b}\right) \frac{K_{t-1}^{b}(j)}{\varepsilon_{t}^{K b}}+\mathcal{P}_{t-1}^{b}(j),
$$

where $\delta^{b}$ measures the resources used in managing bank capital and $\mathcal{P}_{t}^{b}$ represents overall bank profits. $\varepsilon_{t}^{K b}$ is a stochastic shock affecting bank capital. It represents a financial supply-side shock that is important to consider in a policy conflicts analysis, as we will see. After subtracting intra-group

\footnotetext{
${ }^{11}$ Costs in case of negative deviations can be viewed as penalties. In the case of positive deviations, they may refer to the fact that it is costly to have idle capital.

${ }^{12}$ If $\omega_{t}^{E}=\omega_{t}^{H}, B_{t}^{H}(j)=B_{t}^{E}(j)$ and $R_{t}^{b H}(j)=R_{t}^{b E}(j)=R_{t}^{b}$, as in Gerali et al. (2010).
} 
transactions, bank profits are given by

$$
\begin{aligned}
\mathcal{P}_{t}^{b}(j) & =r_{t}^{b H}(j) b_{t}^{H}(j)+r_{t}^{b E}(j) b_{t}^{E}(j)-r_{t}^{d}(j) d_{t}^{P}(j)-\sum_{s=H, E} \mathcal{A}_{b s}\left(r_{t}^{b s}(j)\right) \\
& -\mathcal{A}_{d}\left(r_{t}^{d}(j)\right)-\mathcal{D}_{t}^{v}\left(K_{t}^{b}(j)\right)-\mathcal{D}_{t}^{l e v}\left(K_{t}^{b}(j)\right)
\end{aligned}
$$

Finally, considering the balance-sheet constraint $B_{t}(j)=D_{t}(j)+K_{t}^{b}(j)$ and after some algebra, the problem for the wholesale branch can be reduced to:

$$
\max _{\left\{B_{t}(j), D_{t}(j)\right\}} \mathrm{E}_{0} \sum_{t=0}^{\infty} \Lambda_{0, t}^{P}\left[\sum_{s=H, E} R_{t}^{b s}(j) B_{t}^{s}(j)-R_{t}^{d}(j) D_{t}(j)-\mathcal{D}_{t}^{v}\left(K_{t}^{b}(j)\right)-\mathcal{D}_{t}^{l e v}\left(K_{t}^{b}(j)\right)\right]
$$

where $R_{t}^{b H}$ and $R_{t}^{b E}$ are the internal wholesale loan rates to the households and firms retail loan branches, respectively. Assuming a monetary policy environment of fixed-rate full allotment, $R_{t}^{d}(j)$ corresponds to the policy rate $r_{t}$, which is exogenous to the banking group. According to the first-order conditions, the management branch sets the wholesale lending rates with respect to the policy rate and capital deviations from regulatory requirements:

$$
\begin{aligned}
R_{t}^{b s}(j)=r_{t} & -\kappa_{\text {car }}\left(\frac{K_{t}^{b}(j)}{\omega_{t}^{E} B_{t}^{E}(j)+\omega_{t}^{H} B_{t}^{H}(j)}-v_{t}\right)\left(\frac{K_{t}^{b}(j)}{\omega_{t}^{E} B_{t}^{E}(j)+\omega_{t}^{H} B_{t}^{H}(j)}\right)^{2} \omega_{t}^{s} \\
& -\kappa_{\text {lev }}\left(\frac{K_{t}^{b}(j)}{B_{t}^{E}(j)+B_{t}^{H}(j)}-l e v\right)\left(\frac{K_{t}^{b}(j)}{B_{t}^{E}(j)+B_{t}^{H}(j)}\right)^{2}, \text { for } s \in\{H, E\}
\end{aligned}
$$

These wholesale credit conditions are finally passed on to retail lending rates to households and entrepreneurs $\left(r^{b s}\right)$ through the retail branches of the banking groups, as indicated in the retail banks' programme given by eq. 10, with the first-order conditions given by eq. B39 in Appendix B.

\subsection{Macroprudential and monetary policy rules}

First, we consider that the objective of macroprudential policy is to dampen the credit cycle. To this end, the macroprudential authority can rely on lender- and borrower-based instruments by setting countercyclical CAR requirements and loan-to-value caps on agents' borrowing, respectively.

Countercyclical capital requirements consist of forcing banks to accumulate a capital buffer during good times, which they can draw down to absorb losses in bad times to ensure that credit does not collapse during a crisis. In line with the transposition of the Basel III standards on bank capital adequacy into the Capital Requirements Directive (CRD IV) of European Union law, the $C A R$ requirements in the model are defined by a fixed component denoted $v$ and by a state-contingent component that is equivalent to a countercyclical buffer $(\mathrm{CCyB})$. This time-varying buffer is increased or decreased with respect to the credit-to-GDP gap, or "Basel gap", denoted $\frac{\widetilde{B_{t}}}{Y_{t}}$. Hence, the CAR rule is given by:

$$
v_{t}=\left(v_{t-1}\right)^{\rho_{v}}\left[v\left(\frac{\widetilde{B_{t}}}{Y_{t}}\right)^{\chi_{c c y b}}\right]^{\left(1-\rho_{v}\right)}
$$

where $\chi_{c c y b}>0$ represents the strength of the response of the CAR requirements to the Basel gap. The parameter $\rho_{v}$ captures the gradual adjustment of $C A R$ requirements that is observed in practice, as shown in Figure D1 in Appendix D. In the steady state, the CAR requirement is equal to the fixed component $v$. One original feature of our approach is to consider a model-consistent Hodrick-Prescott 
(HP) filter for computing the credit-to-GDP gap. Technical details are provided in Appendix E.

In addition, the macroprudential package in the model includes two state-dependent loan-to-value (LTV) caps: one for households and one for firms. Time-varying LTV caps for mortgage and business loans aim to dampen the credit cycle by reducing the procyclical link between asset (housing and physical capital) prices and credit. Hence, the caps are supposed to react countercyclically to the sectorial HP-based credit-to-GDP gap as follows:

$$
L T V_{t}^{s}=\left(L T V_{t-1}^{s}\right)^{\rho_{l t v}^{s}}\left[L T V^{s}\left(\frac{\widetilde{B_{t}^{s}}}{Y_{t}}\right)^{\chi_{l t v}^{s}}\right]^{\left(1-\rho_{l t v}^{s}\right)}
$$

where $\chi_{l t v}^{s}$ is the reaction parameter assigned to the respective sectoral credit-to-GDP gap, with $s \in\{H, E\} . \chi_{l t v}^{s}<0$, such that a positive sectoral credit-to-GDP gap would tighten the corresponding loan-to-value limit. The parameter $\rho_{l t v}^{s}$ captures the gradual adjustment of LTV that is observed in practice, as shown in Figure D1 in Appendix D. Note that the regulatory constraints are binding, as in most of the existing studies (see, e.g., Mendicino et al., 2018; Alpanda and Zubairy, 2017). It is crucial that macroprudential constraints are actually operational to identify potential conflicts.

Finally, the objective of monetary policy is to stabilize inflation and the business cycle. To this end, the central bank sets the nominal policy rate $r_{t}$ following a Taylor-type rule such as

$$
\frac{1+r_{t}}{1+r}=\left(\frac{1+r_{t-1}}{1+r}\right)^{\rho_{r}}\left(\frac{\pi_{t}}{\pi}\right)^{\chi_{\pi}\left(1-\rho_{r}\right)}\left(\widetilde{Y}_{t}\right)^{\chi_{y}\left(1-\rho_{r}\right)}
$$

where $\chi_{\pi}$ and $\chi_{y}$ are the response parameters to deviations of inflation $\pi_{t}$ from its steady state $\pi$ and to the model-consistent HP-based output gap $\tilde{Y}_{t}$, respectively. The parameter $\rho_{r}$ captures the degree of interest-rate smoothing, and $r$ is the steady-state value of the policy rate.

\subsection{Calibration}

The calibration of the structural parameters is reported in Table F1 in Appendix F. Values are largely based on Gerali et al. (2010), with a few exceptions that are noted below. Markups on lending rates $\varepsilon^{b s} /\left(\varepsilon^{b s}-1\right)$ are set to 1.15. Absent consensus on the underlying elasticities, these values prevent the exaggeration of banks' reaction to monetary and macroprudential policies. Following Gambacorta and Karmakar (2018), the adjustment cost parameter related to the leverage ratio is set to 7.63, while that relative to the CAR requirements is fixed to 50. Next, combining banks' capital (eq. B29) and profits (eq. B33) implies a steady-state consistent value of 0.084 for $\delta^{b}$, the proportion of resources used in managing bank capital.

The calibration of the macroprudential instruments, reported in Table F2, is based on official regulations prevailing in the euro area, on empirical evidence and on the calibration used in previous studies (See, e.g., Iacoviello and Neri, 2010; Iacoviello, 2015; Rubio and Carrasco-Gallego, 2014). In this way, we set the steady state of the loan-to-value caps for households and firms to 0.8 and 0.9 , respectively, while the steady-state capital adequacy ratio $(v)$ is set to $8 \% .{ }^{13}$ This implies a steadystate leverage ratio equal to 6.91\%, as demonstrated by equation C2 of Appendix C. Moreover, in line with the recommendations of the Basel Committee on Banking Supervision for computing risk-

\footnotetext{
${ }^{13}$ Setting a CAR to $8 \%$ means that the capital conservation buffer of $2.5 \%$ is ignored. However, this does not affect the dynamics of the model and hence the results that we find later on.
} 
weighted assets, according to the standardized approach, the steady-state risk weights for claims on residential property and corporations, $\omega^{H}$ and $\omega^{E}$, are equal to 0.35 and 1.0 , respectively. ${ }^{14}$ Last, following Angelini et al. (2014), the sensitivities of household and firm risk weights to the business cycle $\left(\chi_{s}\right)$ are set to -15 and 10, respectively, and the parameters of persistence $\left(\rho_{s}\right)$ are calibrated to 0.94 and 0.92 , respectively.

Finally, as our analysis consists of identifying some policy side effects conditionally on the strength of the reactions of policymakers, we do not set unique values but rather ranges of values for the reaction parameters of the policy rules. For the monetary policy rule, the range covers most of the empirical and optimized values found in the literature, namely, $[1.7 ; 5.0]$ for $\chi_{\pi}$ and $[0 ; 5.0]$ for $\chi_{y}$. Benchmarks are missing for macroprudential policy parameters, as studies are scarce. ${ }^{15}$ Hence, we consider wider intervals to be as exhaustive as possible: $\chi_{c c y b}$ varies between $[0 ; 20]$, while $\chi_{l t v}^{s}$ lies in the range $[-20 ; 0]$, as in Lambertini et al. (2013). Finally, the parameters $\rho_{v}$ and $\rho_{l t v}^{s}$ are set to 0.99, in accordance with the very high gradualism of macroprudential decisions that is observed in practice (see Figure D1 in Appendix D), and in line with Burlon et al. (2018).

\section{Responses of the model to a selection of representative shocks}

Our investigation of policy conflicts is based on the four different shocks embedded in the model. This section aims to justify the choice of these shocks by analysing in depth their transmission channels and macroeconomic effects.

Two of these shocks, i.e., housing preference $\left(\varepsilon_{t}^{h}\right)$ and productivity $\left(\varepsilon_{t}^{a}\right)$ shocks, can be viewed as real shocks. The two other, namely, bank capital $\left(\varepsilon_{t}^{K b}\right)$ and collateral $\left(\varepsilon_{t}^{m}\right)$ shocks, are more financially oriented. This distinction is important given the nature of the objectives of monetary policy and macroprudential policies. From another perspective, productivity and bank capital shocks are both supply-side shocks, with widespread impacts on the economy. In contrast, housing preference and collateral shocks are demand-side shocks. Moreover, they can be viewed as sectoral shocks, as they are initially circumscribed to the housing market. Finally, as reported in Table 1, which summarizes the impulse response functions (IRFs) that are exhibited below, these four shocks are interesting because they embrace all possible configurations in terms of variation and correlations among the three objective variables.

Before we plot the IRFs, note that for a better understanding of the effects of the policies and for an easier comparison with the existing studies based on the Gerali et al. (2010) framework ${ }^{16}$, two versions of the model are considered, namely, one with and one without countercyclical macroprudential rules (i.e., $\chi_{l t v}^{E}=\chi_{l t v}^{H}=\chi_{c c y b} \neq 0$ or $=0$ in eqs. 17 and 18). Beyond the information that the IRFs provide on the dynamics of the model, they can deliver preliminary indications on potential policy conflicts.

\footnotetext{
${ }^{14}$ See https://www.bis.org/basel_framework/chapter/CRE/20.htm?inforce=20191215.

${ }^{15}$ Angelini et al. (2014) find an optimal value of $\chi_{c c y b}$ between $[2.2-7.0]$, depending on the policy preferences and shocks. Lozej et al. (2018) and Gelain and Ilbas (2017) set this parameter to between [0;2] and [2.5; 7.2], respectively. Rubio and Carrasco-Gallego (2014) find an optimal value of 0.8 for $\chi_{l t v}$, while Burlon et al. (2018) set a value equal to 0.5 .

${ }^{16}$ See, in particular, Gambacorta and Karmakar (2018); Chen and Columba (2016); Angelini et al. (2014).
} 
Table 1: Summary of the responses of output, inflation and the credit gap to four alternative shocks

\begin{tabular}{|c|c|c|c|c|c|c|}
\hline \multirow{3}{*}{ Shock type } & \multirow{2}{*}{\multicolumn{3}{|c|}{$\begin{array}{c}\text { Responses } \\
\text { of }\end{array}$}} & \multicolumn{3}{|c|}{ Correlations } \\
\hline & & & & Output & Output & Inflation \\
\hline & Output & Inflation & Basel gap & Inflation & Basel gap & Basel gap \\
\hline Housing preference shock (-) & $\uparrow$ & $\uparrow$ & $\downarrow$ & + & - & - \\
\hline Productivity shock $(+)$ & $\uparrow(\downarrow)$ & $\downarrow$ & $\uparrow$ & - & + & - \\
\hline Bank capital shock $(-)$ & $\downarrow$ & $\uparrow$ & $\downarrow$ & - & + & - \\
\hline Collateral shock $(+)$ & $\uparrow(\downarrow)$ & $\uparrow(\downarrow)$ & $\uparrow$ & + & + & + \\
\hline
\end{tabular}

Note: This table provides a summary of the initial responses (increase $\uparrow$ or decrease $\downarrow$ ) of output, inflation and the Basel gap, based on the IRFs of the model, following different shocks. It also provides the signs of the theoretical correlations between pairs of these 3 variables. +/ - refer to a positive / negative shock or correlation. Arrows in parentheses indicate responses that are different in the model with macroprudential rules from the response obtained in the model with no macroprudential rules.

Figure 2: Negative housing preference shock
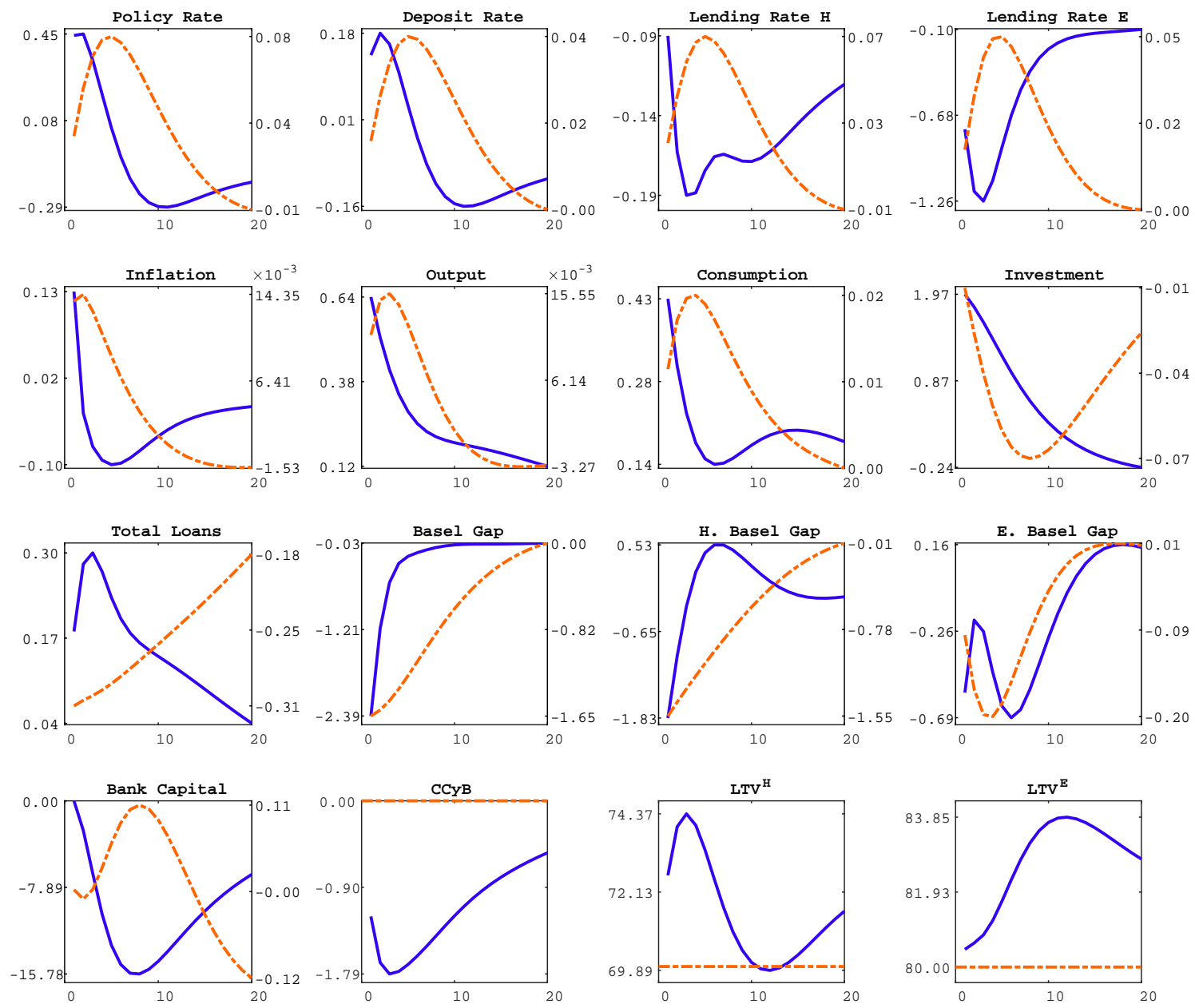

Without Macroprudential rules (RHS)

With Macroprudential rules (LHS)

Housing preference shock Figure 2 reports the response of the model ${ }^{17}$ to a negative housing preference shock $\left(\varepsilon_{t}^{h}<0\right.$ in eq. 1$)$. Let us first consider the configuration with no macroprudential rule. Loans to households are reduced, as this negative shock makes the housing price decline, which

\footnotetext{
${ }^{17}$ In the plots, "H" and "E" refer to households and entrepreneurs, respectively. For instance, "H. Basel gap" and "E. Basel gap" refer to the mortgage and the corporate credit-to-GDP gaps, respectively.
} 
represents a fall in households' collateral. The mortgage credit-to-GDP gap decreases, and the global Basel gap also decreases. Through the substitution effect, the consumption of (impatient) households increases, which stimulates total consumption and explains the rise in total output. Nevertheless, economic growth is dampened by a restrictive monetary policy, which leads to a hike in lending rates. Hence, investment drops. At the same time, bank capital increases as banking profits start rising two periods after the shock, because lending rates increase more than the deposit rate. Interestingly, this shock generates similar macroeconomic dynamics to those of a global demand shock but also has financial consequences, given the importance of housing as collateral.

With countercyclical macroprudential rules, we first observe that LTV requirements are relaxed in response to the decline of sectoral credit gaps. Similarly, the CAR is eased through a reduction in its countercyclical component $(\mathrm{CCyB})$. This accommodative stance leads to a decrease in the lending rate, which stimulates lending. Hence, investment increases in this case, as does consumption. As a result, the increase in output may be even stronger than in the absence of macroprudential rules, but credit is better stabilized.

Figure 3: Positive productivity shock
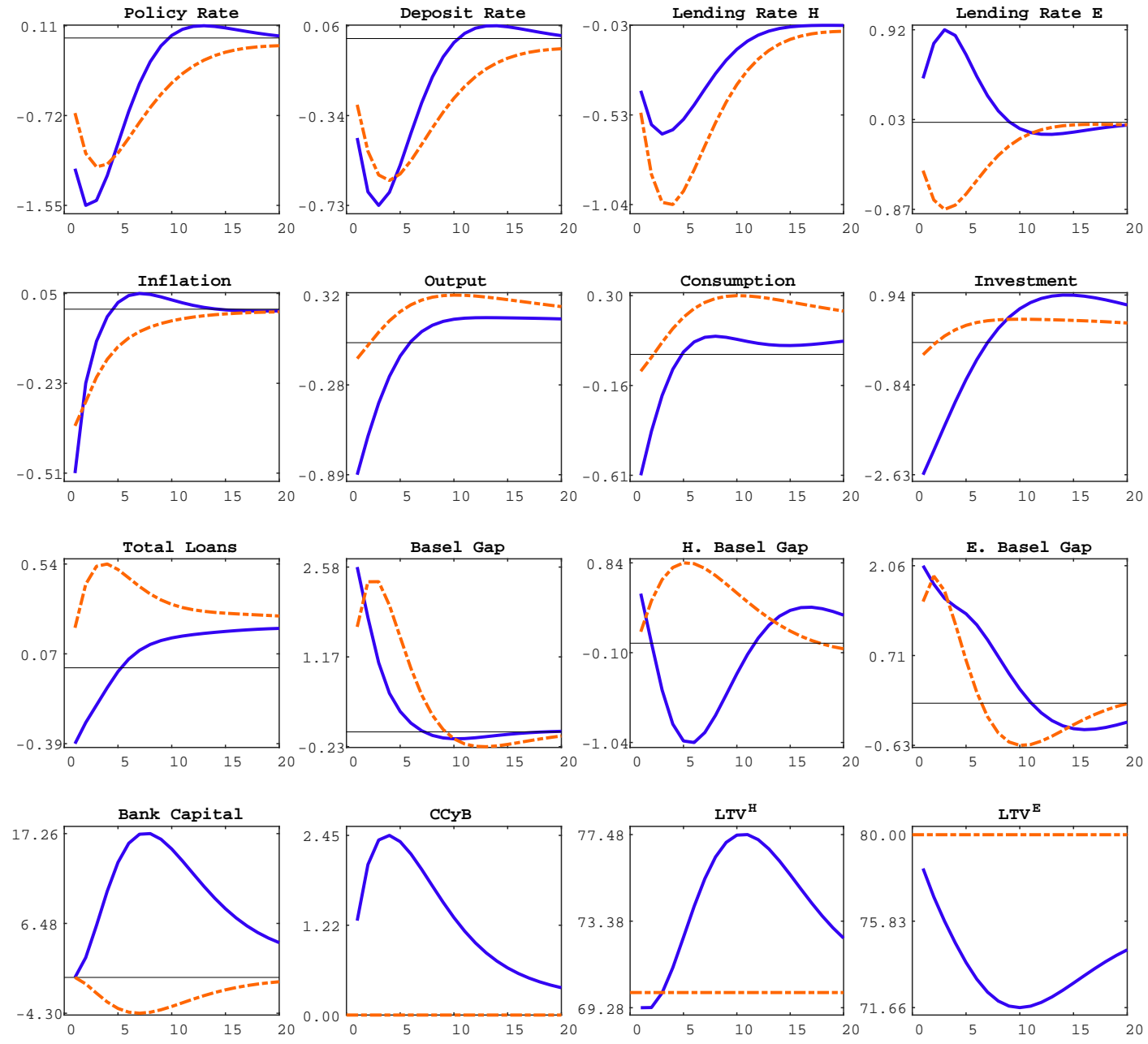

Without Macroprudential rules
Wacroprudential rules

Productivity shock Figure 3 represents the response of the model to a positive technology shock $\left(\varepsilon_{t}^{a}>0\right.$ in eq. 7). As expected, this shock provokes an increase in GDP jointly with a decrease in inflation. The central bank, which reacts more to inflation than to the output gap, cuts its policy rate. 
This lowers retail rates and increases the credit-to-GDP gaps. As a consequence, investment and total consumption rise. Last, bank capital decreases because of the decline of the interest margin (deposit rates decrease less than lending rates).

When state-contingent macroprudential rules are implemented, the CCyB increases in response to the rise in the Basel gap. Hence, banks need to raise their profits to increase their capital. They do so by cutting their retail rates to a lesser extent than they would do in the absence of the CCyB. In this way, they benefit from a growing interest margin. However, this goes against the willingness of the central bank to lower interest rates. Thus, credit conditions are tighter and loans to households are lower than they would be in the absence of macroprudential rules. Furthermore, the debt-deflation mechanism is at work: the relatively higher real debt burden pushes housing demand down. As a consequence, housing prices and collateral values decline. This exacerbates the negative financial effects of the initial shock. Finally, these developments lead to a loosening (tightening) of LTV for households (entrepreneurs), both contributing to smoothing the credit cycle. Note that total output may possibly decrease if the $\mathrm{CCyB}$ and corporate LTV tightening are readily aggressive. This is indicated in Table 1 by a downward arrow in parentheses. Hence, these IRFs already suggest the existence of policy conflicts.

Figure 4: Negative bank capital shock
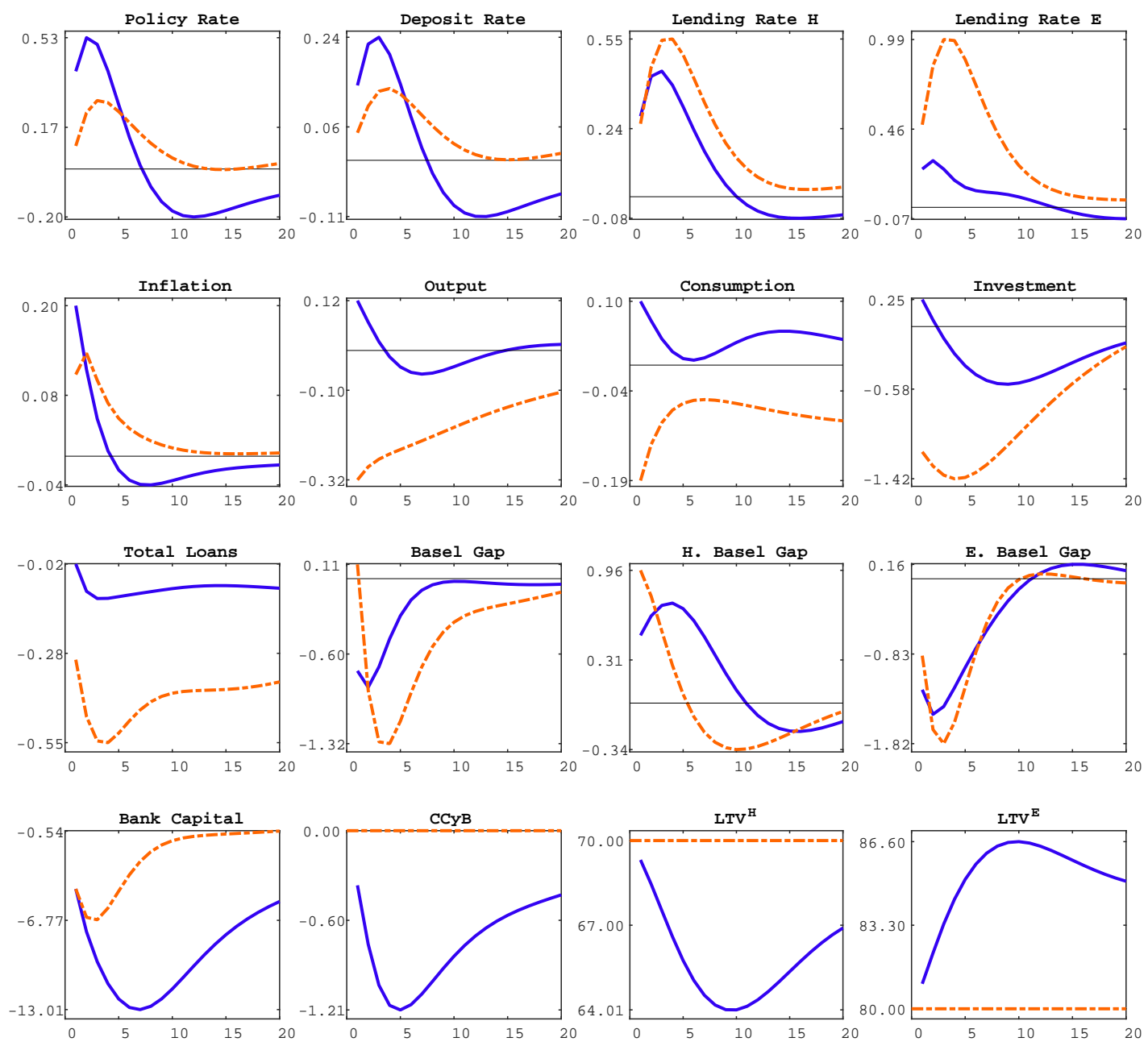

=--=" Without Macroprudential rules

With Macroprudential rules

Bank capital shock Figure 4 reports the response of the model to an exogenous decrease in bank capital (i.e., $\varepsilon_{t}^{K b}>0$ in eq. 13). Interestingly, we find macroeconomic effects close to those obtained 
under the technological shock but with very different transmission channels. Banks have to raise their profits to meet the regulatory CAR by hiking their retail rates. This provokes a reduction in loans to entrepreneurs, which in turn leads to lower investment and consumption. Then, firms increase their labour demand to offset the decrease in capital. Benefiting from higher labour incomes, households consume and invest more in housing, which implies more collateral and ultimately more mortgage loans. However, this does not compensate for the fall in corporate lending. Finally, output and the aggregated Basel gap decrease. Simultaneously, monetary policy is slightly restrictive to fight inflation.

Turning now to active macroprudential policies, we see that the $\mathrm{CCyB}$ is diminished in response to the declining Basel gap. Moreover, LTV caps contribute to smoothing the credit cycle (its trough is halved) and supporting firms' investment and consumption. As a consequence, total consumption does no longer decrease. Monetary policy is initially more restrictive as the output gap and inflation increase. Then, the policy rate is cut, which makes output higher, whereas inflation remains subdued for a while.

Collateral shock Figure 5 shows that a positive collateral shock $\left(\varepsilon_{t}^{m}>0\right.$ in eq. 4$)$, which is equivalent to a de facto increase in LTV, stimulates lending to households and provokes a rise in the Basel gap. Its stimulating macroeconomic effects induce a tightening of monetary policy. The inherent hike in lending rates makes banks' profit and capital increase.

Figure 5: Positive collateral shock
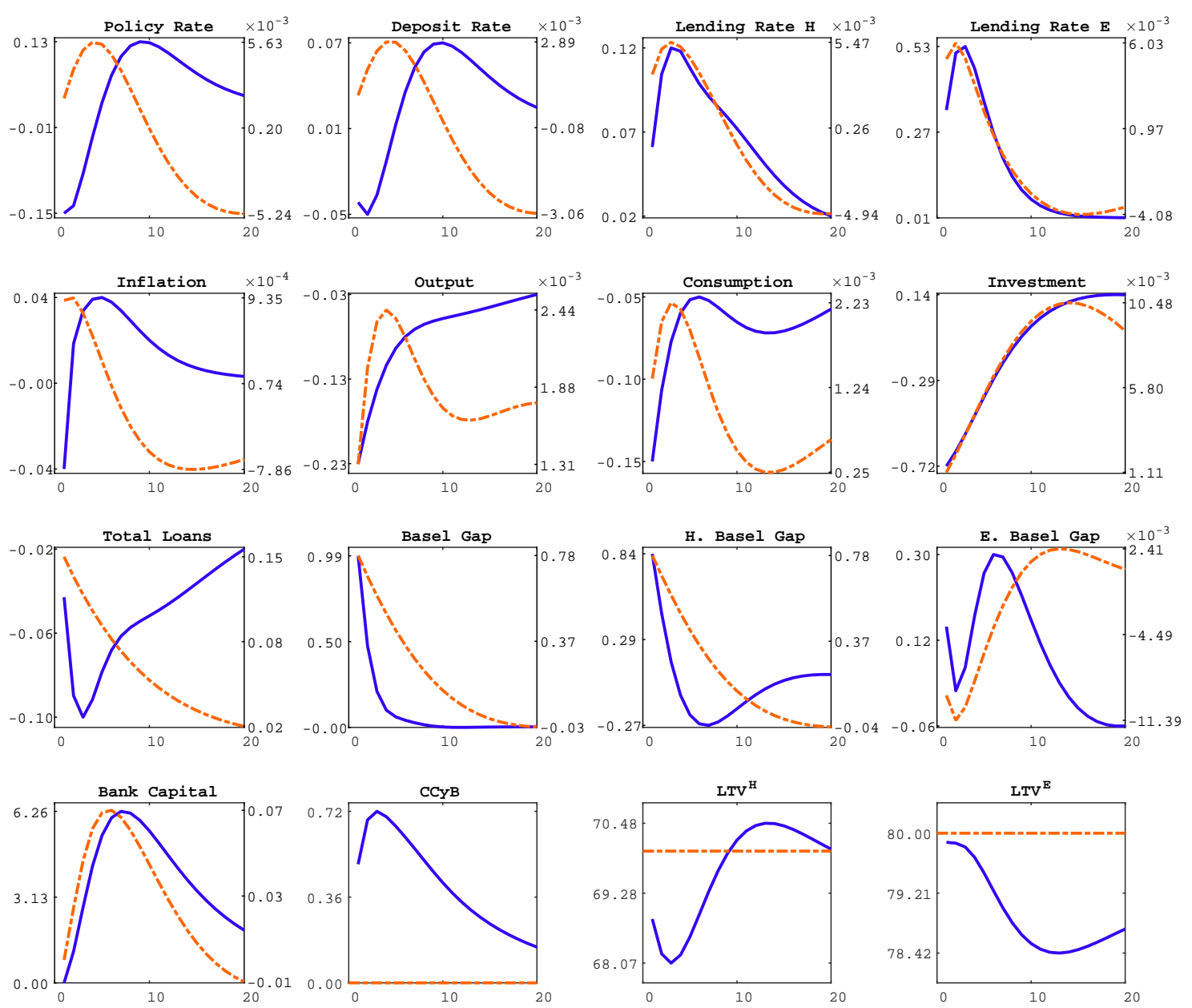

---=-"-Without Macroprudential rules (RHS)

With Macroprudential rules (LHS) 
Regarding macroprudential policies, the policymaker can immediately offset this collateral shock by restricting the mortgage LTV and tightening the CCyB. Meanwhile, impatient households reduce their labour supply, which lowers production. Hence, producers invest and consume less. The inherent fall in output is higher than that in loans, which explains the increase in firms' credit-to-GDP gap. This motivates a tightening of the corporate LTV. Finally, the contraction of economic activity pushes inflation down. As a consequence, monetary policy is relaxed. This shows that implementing countercyclical macroprudential rules can induce changes in the dynamics of the economy and in the stance of monetary policy, with consequences for the stabilization of inflation and output. Again, this illustrates possible policy side effects.

\section{$5 \quad$ Identifying conflicts}

While the IRFs give some preliminary intuitions concerning the side effects of each policy, this section aims to reveal the existence of policy conflicts more formally. To this end, we examine the volatility of the three main objective variables (output, inflation, Basel gap) as the reaction parameters of the macroprudential and monetary policy rules $\left(\chi_{c c y b}, \chi_{l t v}^{E}, \chi_{l t v}^{H}, \chi_{\pi}, \chi_{Y}\right)$ are gradually increased, one by one. We consider a conflict to be a situation in which the theoretical variances of output or inflation increase as the reaction parameter of any macroprudential rule goes up, other reaction parameters being unchanged. In the same way, monetary policy is considered to be at the origin of conflicts when the theoretical variance of the Basel gap increases as the reaction parameters of the monetary policy rule rise, ceteris paribus. The advantage of such an approach is that we do not need to make any assumption on the preferences in policymakers' loss function. Nevertheless, we can show that adverse side effects identified with our simple and effective approach give rise to policy trade-offs, according to policy frontiers based on the usual loss functions, such as those used by Angelini et al. (2014).

\subsection{Conflicts stemming from countercyclical capital requirements}

Figure 6 reveals the potential conflicts arising from using the $\mathrm{CCyB}$ as the policy parameter $\chi_{c c y b}$ increases from 0 to 20 . We observe that implementing a state-contingent CAR is detrimental to the stabilization of output and inflation in most cases. Possibly, in the case of a productivity shock, having a reaction parameter $\chi_{c c y b}$ lower than 3 makes the variances of output slightly decrease, which suggests complementarity between macroprudential and monetary policies' objectives. However, the CCyB generates adverse real side effects for values of $\chi_{c c y b}$ higher than 3 . In the same way, a moderate response of the CCyB to the Basel gap, i.e., $\chi_{c c y b}$ lower than 1.6, is slightly beneficial for the stabilization of output in the case of a bank capital shock. However, this gain is tiny relative to the enormous increase in the variance of output that is observed as $\chi_{c c y b}$ increases beyond 1.6.

The IRFs presented in the previous section can help us understand the source of the conflicts. For instance, in Figure 2, we observe that following a negative housing preference shock, the CCyB decreases in response to the fall in the credit gap. Easing banks' balance-sheet constraints should encourage banks to lower their retail rates. In contrast, monetary policy consists of hiking the policy rate in response to the increase in inflation and output. This should make retail rates increase. Hence, the two policies go in opposite directions. Figure 6 shows that the inherent conflicts are even more important as the $\mathrm{CCyB}$ responds much more strongly to financial imbalances. Similarly, as indicated in Figure 3, the $\mathrm{CCyB}$ is tightened in response to the increase in the Basel gap, following a favourable productivity shock. However, this macroprudential policy orientation conflicts with the accommodative monetary 
Figure 6: Real side effects of the $\mathrm{CCyB}$
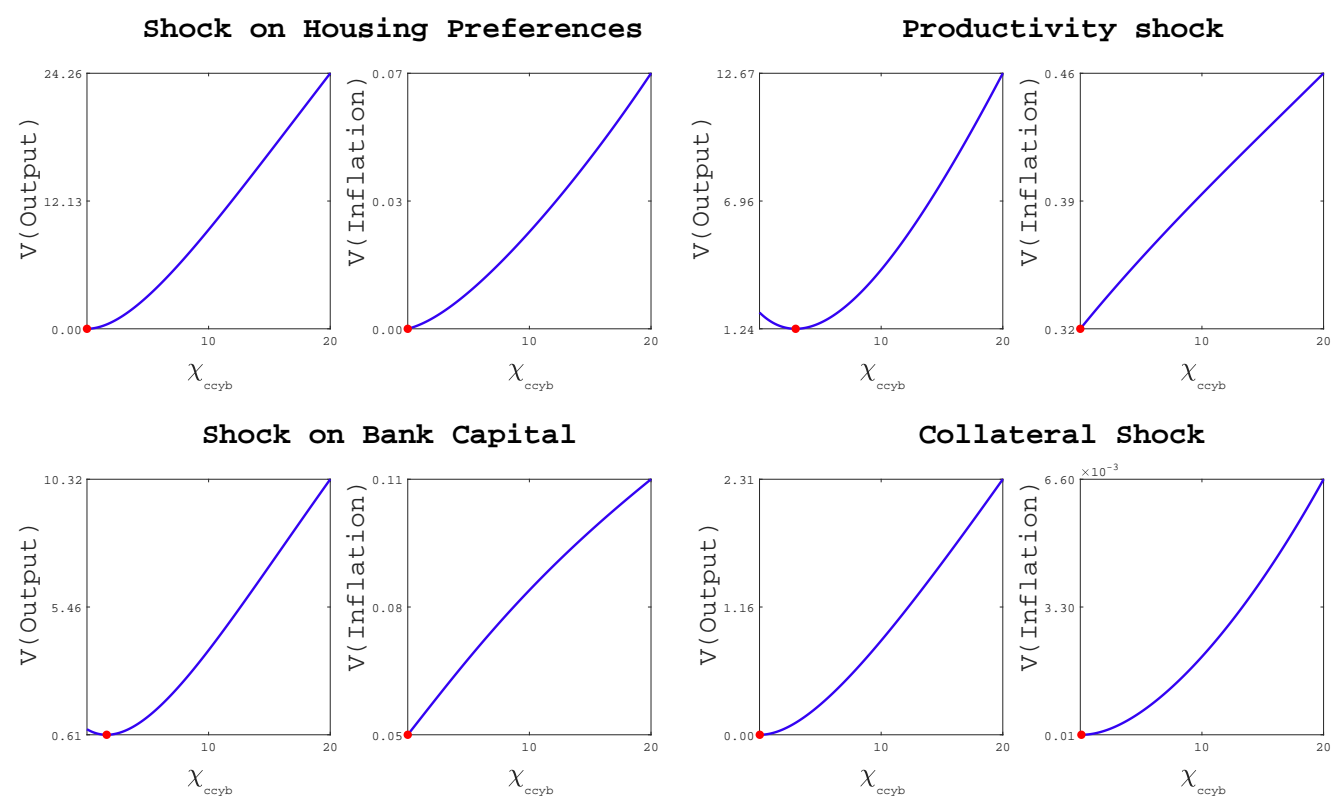

Note: Each plot represents the evolution of the theoretical variance of output or inflation as the reaction parameter $\chi_{c c y b}$ in the $C A R$ rule increases from 0 to 20 in increments of 0.01 , while the policy parameters in the other policy rules remain constant $\left(\chi_{\pi}=1.98, \chi_{y}=0.34, \chi_{l t v}^{H}=\chi_{l t v}^{E}=\right.$ $-1.0)$.

policy stance, motivated by the simultaneous fall in inflation. The higher the policy parameter $\chi_{c c y b}$, the more banks must increase their lending rates to meet the stricter capital requirements, and the higher is the interference with the policy rate cut. This eventually affects the stabilization of inflation.

For illustration purposes, we can show that the conflicts that are identified here can be transposed into policy trade-offs. Following the optimization framework proposed by Angelini et al. (2014), Figure G1 in Appendix G reports the policy frontiers related to the six clear-cut conflicting cases identified in Figure 6. As evidence of trade-offs between macroprudential and monetary policies' objectives, we can see that increasing the weight of credit gap stabilization in the loss function of the policymaker makes the variance of the Basel gap decrease, at the expense of higher volatility of output and/or inflation.

\subsection{Conflicts stemming from loan-to-value caps}

Figure 7 reports the evolution of the variances of output and inflation as the reaction parameter $\chi_{l t v}^{H}$ in the mortgage loan-to-value rule moves from 0 to -20 . Interestingly, we observe that contrary to the $\mathrm{CCyB}$, there are some cases in which the real side effects are clearly favourable: complementarity with monetary policy objectives is found in the case of housing and collateral shocks. For instance, as shown in Figure 2, the LTV cap for households is relaxed in response to the fall in the credit gap following a negative housing preference shock. By stimulating household demand for loans, this accommodative policy pushes lending rates up. This orientation is consistent with the increase in the monetary policy rate, which aims at curbing inflation and the output gap. ${ }^{18}$ Next, inflation and output also benefit from LTV caps to households in the case of a productivity shock, while the variance of output slightly increases as $\chi_{l t v}^{H}$ exceeds 12 in absolute value. Finally, we find only one clear-cut

\footnotetext{
${ }^{18}$ Furthermore, the stronger the reaction of the LTV cap, the more it compensates for the adverse real effects of the $\mathrm{CCyB}$ found in case of a housing preference shock.
} 
conflict, which concerns the stabilization of inflation in the case of a bank capital shock. The variance of output also increases, but it tends to slightly decrease as $\chi_{l t v}^{H}$ becomes very high (higher than 10 in absolute value).

Some of the side effects found in Figure 7 are transposed in terms of policy frontiers in Figure G2 in Appendix G. In this way, we can see, for instance, that the variances of output, inflation and the credit gap all decrease as the relative weight of the credit gap stabilization objective increases in the policymaker's loss function in the case of housing preference and collateral shocks. In addition, we can show that the stabilization of inflation benefits from a higher relative weight of the macroprudential objective in the case of a productivity shock. Finally, as evidence of a policy trade-off, we show that the variance of the credit gap is reduced at the expense of higher volatility of inflation in the case of a bank capital shock.

Figure 7: Real side effects of the LTV cap for households
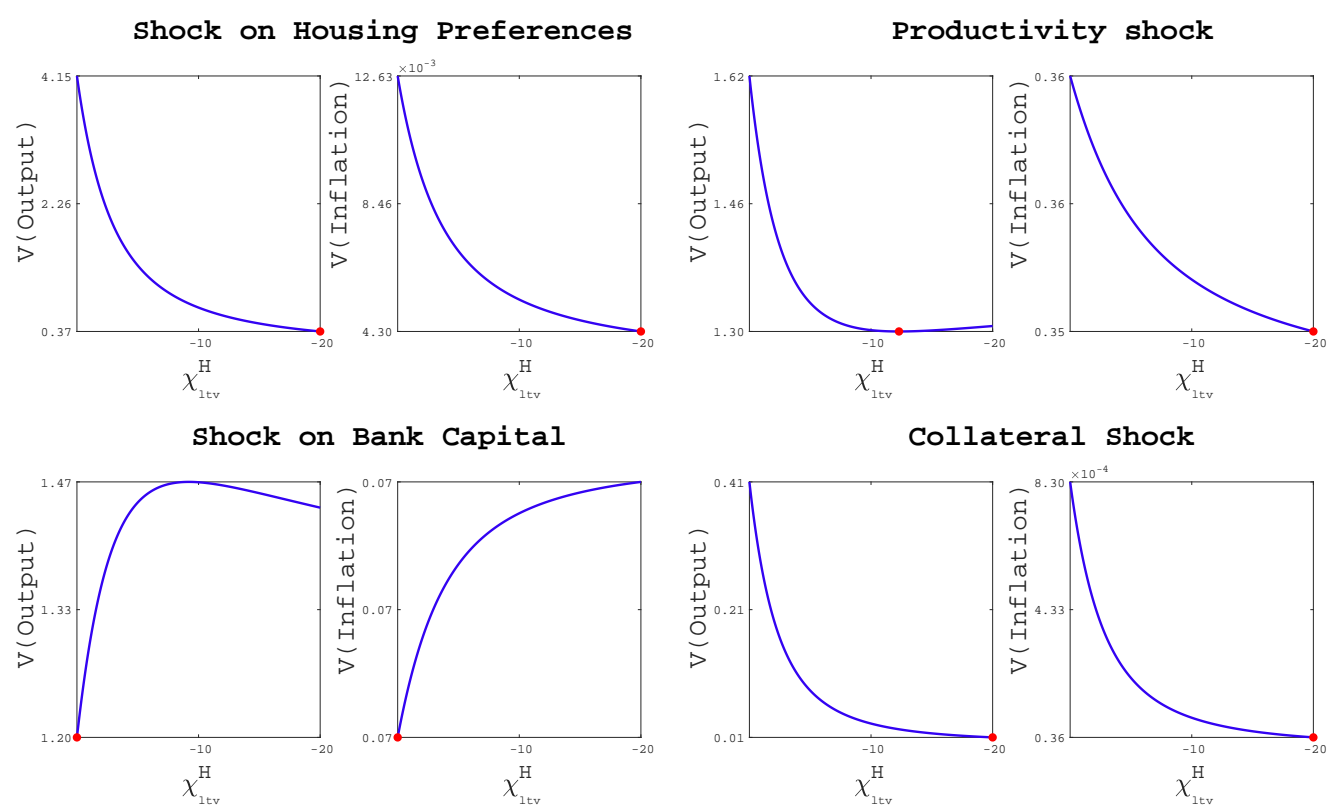

Note: Each plot represents the evolution of the theoretical variance of output or inflation as the reaction parameter $\chi_{l t v}^{H}$ in the $L T V^{H}$ rule evolves from -20 to 0 in increments of 0.01, while the policy parameters in the other policy rules remain constant $\left(\chi_{\pi}=1.98, \chi_{y}=0.34, \chi_{l t v}^{E}=-1.0, \chi_{c c y b}=5.0\right)$.

Next, in light of Figure 8, we find that the LTV cap for entrepreneurs also causes few conflicts. The only clear-cut adverse side effect concerns output stabilization in the case of collateral shocks. This conflict arises because monetary policy seeks to support inflation and output by encouraging demand from entrepreneurs. However, at the same time, the LTV cap for entrepreneurs is tightened, which brings investment and consumption down even more. Conflicts with monetary policy objectives may also arise in the case of productivity and bank capital shocks but only if the reaction of the corporate LTV rule is relatively aggressive. In contrast, inflation benefits from the LTV cap for entrepreneurs in the case of a bank capital shock. As shown in Figure 4, the corporate LTV is loosened in response to the fall in the entrepreneurs' sectoral Basel gap, following a negative bank capital shock. This intends to encourage loan demand and should push lending rates up. This stance is consistent with the policy rate hike intended to curb inflation. Similarly, complementarity is predicted in the case of a housing preference shock. 
Figure 8: Real side effects of the LTV cap for firms
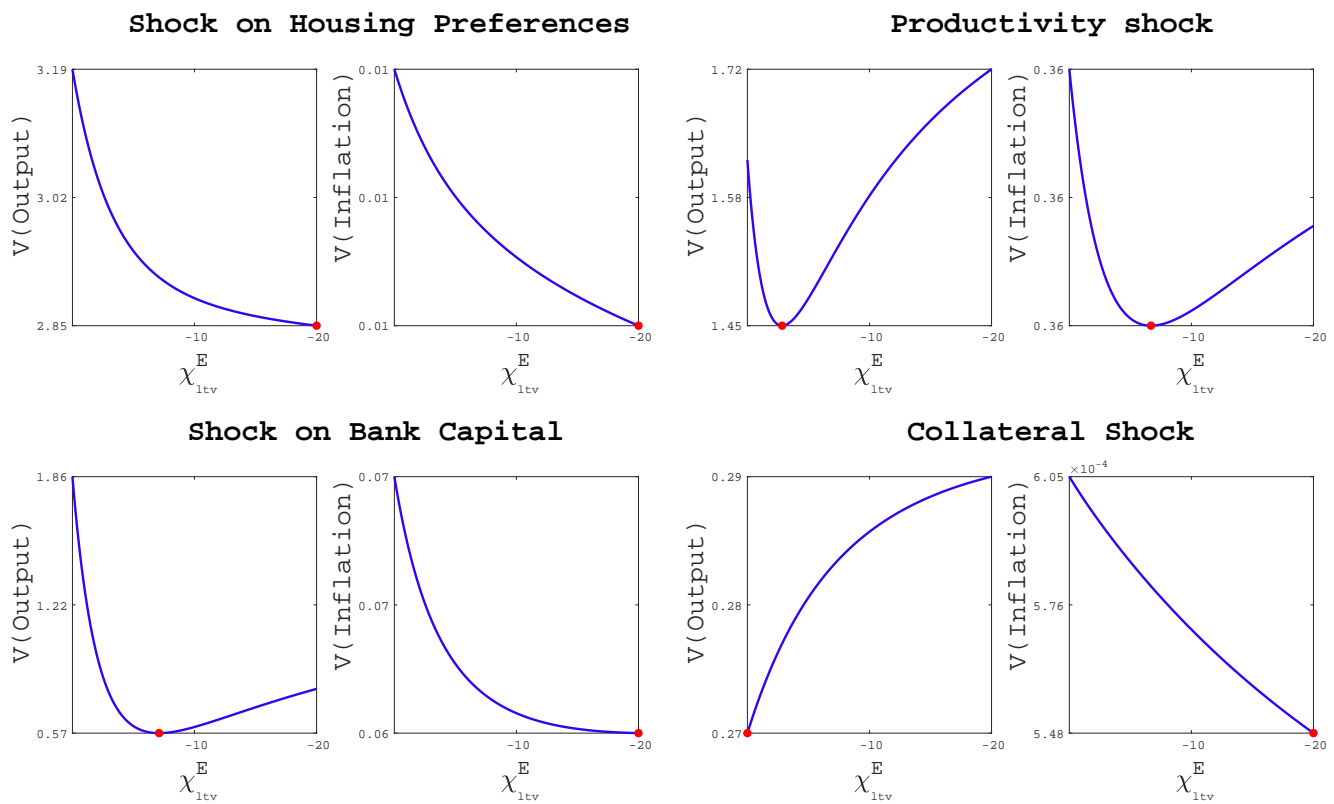

Note: Each plot represents the evolution of the theoretical variance of output or inflation as the reaction parameter $\chi_{l t v}^{E}$ in the $L T V^{E}$ rule evolves from -20 to 0 in increments of 0.01 , while the policy parameters in the other policy rules remain constant $\left(\chi_{\pi}=1.98, \chi_{y}=0.34, \chi_{l t v}^{H}=-1.0, \chi_{c c y b}=5.0\right)$.

The policy frontiers in Figure G3 in Appendix G illustrate this complementarity between the corporate LTV and monetary policy in the case of a housing preference shock: the variances of the credit gap and inflation decrease as the relative weight of the macroprudential objective in the policy loss function increases. In contrast, more weight given to the objective of credit gap stabilization is shown to be detrimental to the stabilization of output, evidencing a trade-off that occurs in the case of a collateral shock.

\subsection{Conflicts stemming from monetary policy}

Figure 9 represents the impact of the two policy parameters of the monetary policy rule on the variance of the credit gap. We first notice that the reaction to inflation changes creates conflicts in all cases. Let us consider the productivity shock as an example. The monetary policy rate is cut to support inflation (see Fig. 3). This accommodative monetary policy stance is likely to decrease retail rates and stimulate loans. However, macroprudential policy becomes more restrictive in response to the increase in the Basel gap. This aims to raise lending rates and reduce excess loans, which is opposite to the objective of monetary policy. Similarly, in the case of (negative) housing preference shocks (see Fig. 2), the interest rate hike (motivated by the increase in inflation and the output gap) counteracts the easing stance of macroprudential policy (justified by a decline in the credit gap). This conflict worsens as policymakers react more strongly to inflation.

In contrast, the reaction to output changes is not very detrimental to the stabilization of credit. Complementarities are even found in the case of a bank capital shock, as well as following sectoral shocks, provided that the reaction parameter to output is higher than 0.5. Hence, contrary to the reaction to inflation, a strong reaction to output movements is beneficial for the stabilization of credit, except in the case of a productivity shock. 
Figure 9: Financial side effects of monetary policy

Shock on Housing Preferences

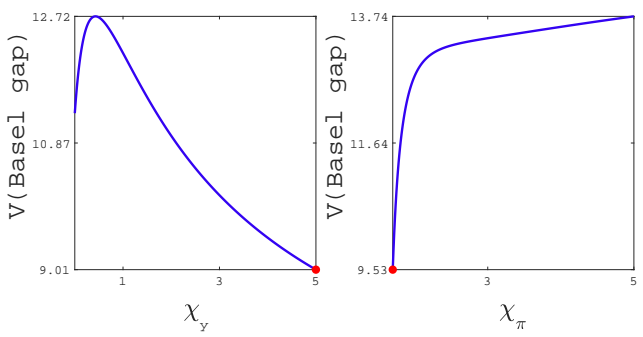

Shock on Bank Capital
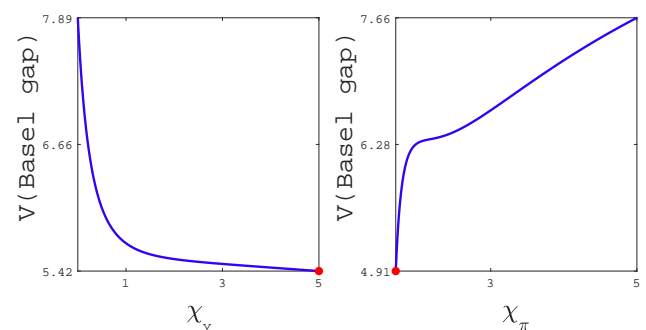

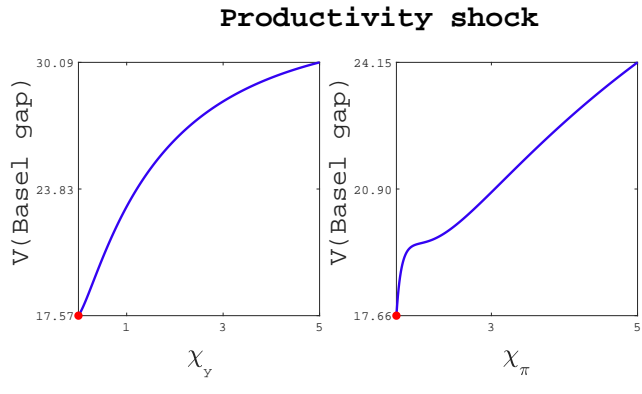

Collateral Shock

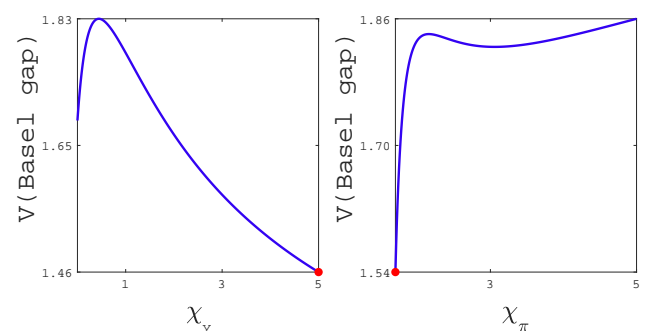

Note: Each plot represents the evolution of the theoretical variance of the Basel gap as the reaction parameters $\chi_{\pi}$ or $\chi_{y}$ in the monetary policy rule evolve over $[1.70,5.0]$ and $[0,5.0]$, respectively, in increments of 0.01 , while the policy parameters in the other policy rules remain constant $\left(\chi_{l t v}^{H}=\chi_{l t v}^{E}=-1.0, \chi_{c c y b}=5.0\right)$.

Figure G4 in Appendix G transposes the four clear-cut conflicts identified in Figure 9 into policy trade-offs. These policy frontiers represent the trade-offs occurring between the two objectives of monetary policy and credit gap stabilization in the case of a productivity shock. We can also see how increasing the relative preference for the objective of inflation makes prices more stable at the expense of higher volatility of the credit gap in the case of housing preference and bank capital shocks.

\section{Assessment and discussion}

This section aims to provide an assessment of the results obtained so far and to reveal general trends governing the policy conflicts. First, Table 2 reports all the conflicts originating with macroprudential policy. We observe that the macroprudential instruments may be particularly detrimental to the stabilization of inflation and output in the case of technology and bank capital shocks. Both are supply-side and global shocks. It is as if the simultaneous and uncoordinated reaction of all the policy instruments to such global shocks triggers cacophony. From the perspective of the instruments, we observe that the $\mathrm{CCyB}$ generates real side effects in most cases, particularly if it reacts strongly to its target. ${ }^{19}$ In contrast, LTV caps cause few conflicts. They are even complementary to monetary policy in cases of sectoral shocks, such as housing and collateral shocks.

Second, Table 3 reports the conflicts originating with the monetary policy rule. We can see that the reaction to inflation is always detrimental to the credit cycle. In contrast, the response to the output gap can induce complementarity: the stronger the response, the greater is the stabilization of the credit-to-GDP gap ${ }^{20}$, except in the case of a productivity shock (which is at the origin of the

\footnotetext{
${ }^{19}$ Note that the adverse real effects of the $\mathrm{CCyB}$ in the case of productivity and bank capital shocks are in line with the findings of Silvo (2019) and Angelini et al. (2014).

${ }^{20}$ This result can be related to that of Gelain and Ilbas (2017), who conclude that monetary policy should place a
} 
Table 2: Summary of the conflicts stemming from macroprudential policies

\begin{tabular}{l|cc|cc|cc|cc}
\hline \hline Shock: & \multicolumn{2}{|c|}{ Housing preference } & \multicolumn{2}{|c|}{ Productivity } & \multicolumn{2}{c|}{ Bank capital } & \multicolumn{2}{c}{ Collateral } \\
\hline & $V(Y)$ & $V(\pi)$ & $V(Y)$ & $V(\pi)$ & $V(Y)$ & $V(\pi)$ & $V(Y)$ & $V(\pi)$ \\
\cline { 2 - 8 }$\chi_{c c y b}$ & $\bullet$ & $\bullet$ & $\bullet$ & $\bullet$ & $\bullet$ & $\bullet$ & $\bullet$ & $\bullet$ \\
$\chi_{l t v}^{H}$ & & & $\bullet$ & & $\bullet$ & $\bullet$ & & \\
$\chi_{l t v}^{E}$ & & & $\bullet$ & $\bullet$ & $\bullet$ & & $\bullet$ & \\
\hline \hline
\end{tabular}

Note: - indicates conflicts, i.e., an increase in the variance of inflation or output as the concerned macroprudential policy parameter increases. means that a conflict exists only above a given value of the concerned policy parameter. 1 indicates negative side effects only below a certain threshold of the concerned policy parameter.

usual trade-off between inflation and output). However, as monetary policy is primarily driven by the objective of inflation, a trade-off between monetary and macroprudential policies is likely to occur most of the time.

Table 3: Summary of the conflicts stemming from monetary policy

\begin{tabular}{l|cc|cc|cc|cc}
\hline \hline Shock: & \multicolumn{2}{|c|}{ Housing preference } & \multicolumn{2}{|c|}{ Productivity } & \multicolumn{2}{c|}{ Bank capital } & \multicolumn{2}{c}{ Collateral } \\
\hline \multirow{4}{*}{$\chi_{y}$} & $V($ B.gap $)$ & Prob. & $V($ B.gap $)$ & Prob. & $V($ B.gap $)$ & Prob. & $V($ B.gap $)$ & Prob. \\
\cline { 2 - 8 }$\chi_{\pi}$ & $\bullet$ & $\bullet$ & $\bullet$ & $\bullet$ & & & $\bullet$ & 0 \\
\hline \hline
\end{tabular}

Note: "B.gap" means "Basel gap". @ indicates conflicts, i.e., an increase in the variance of the Basel gap as the concerned monetary policy parameter increases. indicates negative side effects only below a certain threshold for the concerned policy parameter.

Hence, our comprehensive assessment reveals that monetary policy and state-contingent capital asset requirement policies are responsible for conflicts in many circumstances. To understand why, it is worth noting that these two instruments share the same main transmission channel. Indeed, by influencing the wholesale (or intra-group) deposit rate, the policy rate impacts banks' balance sheets, which in turn implies variations in retail interest rates. In the same way, CCyB activation demands adjustment of banks' balance sheets through the adjustment of the interest margin. Then, by influencing retail rates, these two policies "get in all the cracks" of the economy. ${ }^{21}$ As a consequence, they are more likely to generate side effects. However, as shown in the last column of Table 1, their respective targets - inflation for monetary policy and the credit gap for the $\mathrm{CCyB}$ - always move in the opposite directions from each other (except in the case of collateral shocks). Thus, most of the time, the side effects turn out to be conflicts. Finally, as output and credit gaps tend to move in the same direction, monetary policy would provoke fewer conflicts if a greater weight is assigned to the output stabilization target.

In contrast, mortgage and corporate LTV caps can be viewed as targeted measures. They can be set independently to regulate either household or corporate financing. Moreover, they affect credit volumes (and not interest rates directly). Thus, these sectoral policies are less likely to generate conflicts. This clearly appears in Table 2, where we can see that the LTV rules do not generate adverse real effects when the shocks are specific to the housing market (i.e., housing preference and collateral shocks),

\footnotetext{
high weight on the output gap to achieve the best possible outcome in the absence of policy coordination.

${ }^{21}$ This is the way that J. Stein, the former Fed governor, describes the widespread transmission of monetary policy rate changes, which "may reach into the corners" of the economy and the financial markets through the impact on all market rates (Stein, 2013).
} 
with the only exception being the corporate LTV in the case of a collateral shock. Therefore, from this perspective, it seems that taming lending practices provokes fewer conflicts than managing capital buffers.

\section{Extension to extreme vulnerabilities}

Extreme real and financial vulnerabilities, instead of or in addition to the stabilization of macroeconomic and credit cycles, may be a concern for policymakers. Theoretically, this is the case for a robust policymaker who aims to protect the economy against worst-case scenarios (see, e.g., Ajello et al., 2019). Therefore, we now consider crisis probability and growth-at-risk as two alternative objectives.

\subsection{Another financial objective: Crisis probability}

So far, we have considered the most commonly accepted financial objective for macroprudential policy: smoothing the credit cycle. However, dealing with financial vulnerability may refer to different objectives in practice. ${ }^{22}$ One way of ensuring resilience may consist of reducing the risk of a crisis occurring. This is the macroprudential objective that we consider now. In line with Aikman et al. (2019) and Benigno et al. (2020), we assume that the probability of a financial crisis $\mathcal{P}_{t}^{c}$ follows a logistic function and increases as the credit gap rises and/or as banking capital decreases, with the respective elasticities denoted $h_{1}$ and $h_{2}$, such that

$$
\mathcal{P}_{t}^{c}=\frac{\exp \left(\mathcal{C}+h_{1}\left(\frac{\widetilde{B_{t}}}{Y_{t}}\right)+h_{2}\left(\frac{K_{t}^{b}}{B_{t}}-\text { lev }\right)\right)}{1+\exp \left(\mathcal{C}+h_{1}\left(\frac{\widetilde{B_{t}}}{Y_{t}}\right)+h_{2}\left(\frac{K_{t}^{b}}{B_{t}}-\text { lev }\right)\right)}
$$

The constant $\mathcal{C}$ is calibrated such that the probability of a crisis in the steady state is $10,71 \%{ }^{23}$ This probability can also be viewed as a simple indicator of financial vulnerabilities combining the credit gap and banks' leverage.

Then, we compute distributions of crisis probability, based on 1000 simulations of 200 periods, conditional on the ranges of values for the two policy parameters of the monetary policy rule and on the four key shocks considered so far. Instead of dealing with second moments, we now focus on the 95th percentile of crisis probability as a measure of extreme risk of a banking crisis. Figure 10 indicates that the results are exactly the same as those found with the variance of the Basel gap as an objective: while the reaction to the output gap may decrease extreme probabilities of crisis, a stronger reaction to inflation always worsens the worst-case scenario. This means that our previous results still hold while considering a mix of the Basel gap and banks' leverage, in a non-linear way, as a policy objective.

\footnotetext{
${ }^{22}$ For instance, Kashyap and Siegert (2020) highlight that "absent any agreed upon summary indicators, different policymakers are free to cherry-pick their own preferred indicators of vulnerabilities".

${ }^{23}$ Note that the level of crisis probability per se is less important than the way it reacts to the parameters of the monetary policy rule.
} 
Figure 10: Probability of a crisis conditional on the monetary policy rule
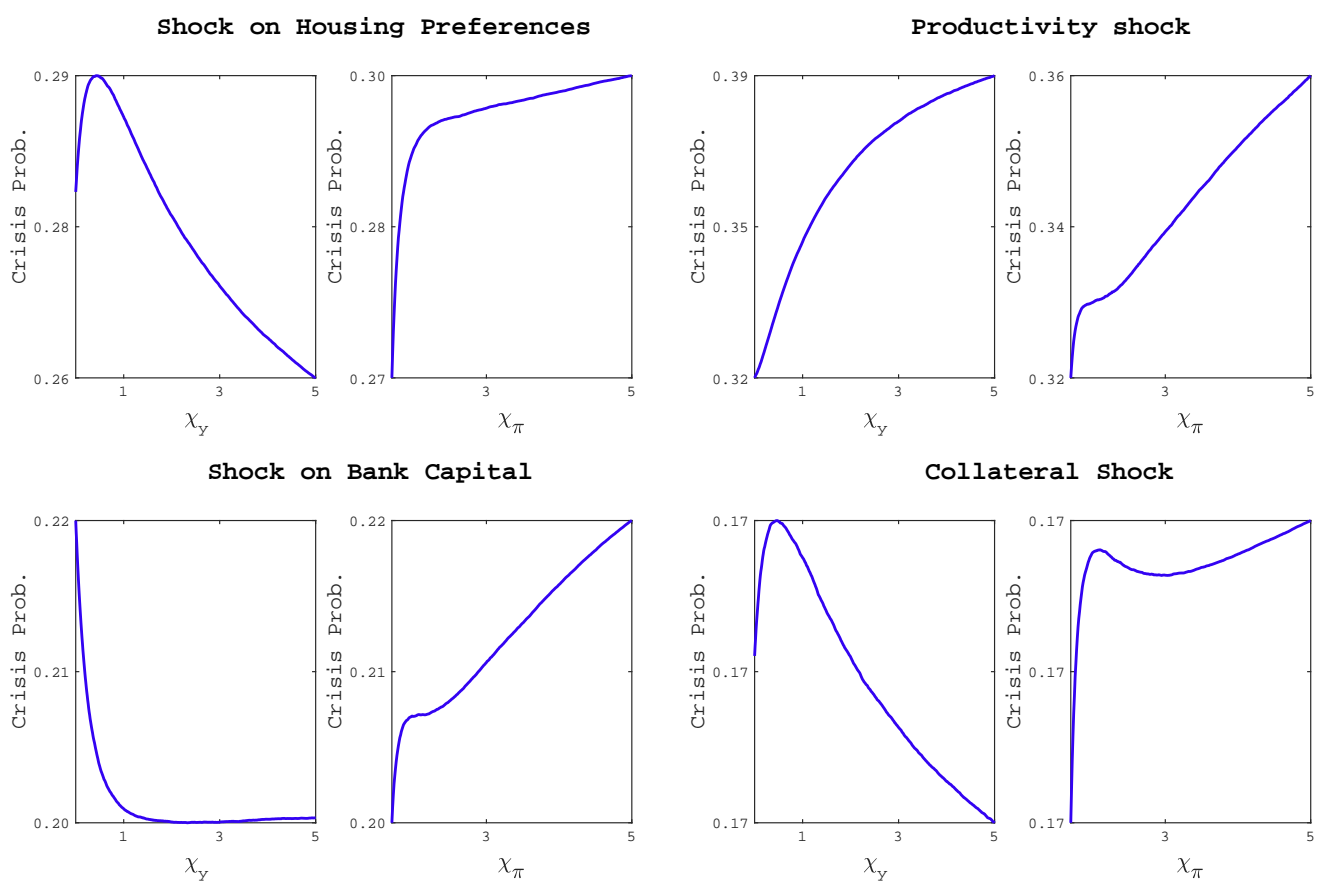

Note: Each plot represents the evolution of the 95th percentile of the probability of a crisis as the reaction parameters of the interest policy rule, $\chi_{\pi}$ and $\chi_{y}$, evolve over $[1.70,5.0]$ and $[0,5.0]$, respectively, in increments of 0.01 . The policy parameters in the macroprudential policy rules remain constant $\left(\chi_{l t v}^{H}=\chi_{l t v}^{E}=-1.0, \chi_{c c y b}=5.0\right)$. Initial conditions are neutralized by excluding the first 100 periods.

\subsection{Another real objective: Growth-at-risk}

Reducing extreme real risk may be an objective for central banks. It can, at least, hardly be neglected. For example, central banks dramatically cut their key rates and prompted packages of unconventional measures in response to the global financial crisis and the COVID-19 crisis, with the same objective of limiting economic depression and deflation, i.e., to mitigate the severely adverse scenario. This leads to a focus on growth-at-risk $(\mathrm{GaR})$ as an alternative real objective of monetary policy. GaR is the probability of GDP growth $\left(\Delta Y_{t}\right)$ falling below a given threshold $\alpha$, such that

$$
\text { Probability }\left(\Delta Y_{t} \leqslant \operatorname{GaR}_{t}\right)=\alpha
$$

with $\alpha$ often being equal to $5 \%$. In other words, GaR measures the magnitude of a decline in GDP that occurs with a probability of $5 \%$. Adrian et al. (2019) show that this downside risk increases as financial conditions - precisely those that rely on macroprudential policies - worsen. Hence, it is worth assessing how macroprudential measures interact with this possible objective of monetary policy. To this end, we examine whether the 5th percentile of simulated distributions of annualized GDP growth exhibits rightward (meaning complementarity) or leftward (meaning conflict) shifts as the reaction parameter of any macroprudential rule increases, ceteris paribus. ${ }^{24}$

\footnotetext{
${ }^{24}$ As usual in the literature, our model is solved up to first-order only, so that financial vulnerabilities do not play a role in equilibrium. There is no crisis per se in our inherently linear model. However, strongly negative outcomes for GDP growth, which are partly governed by financial conditions, are still possible.
} 
Figure 11: Growth-at-risk conditional on the $\mathrm{CCyB}$
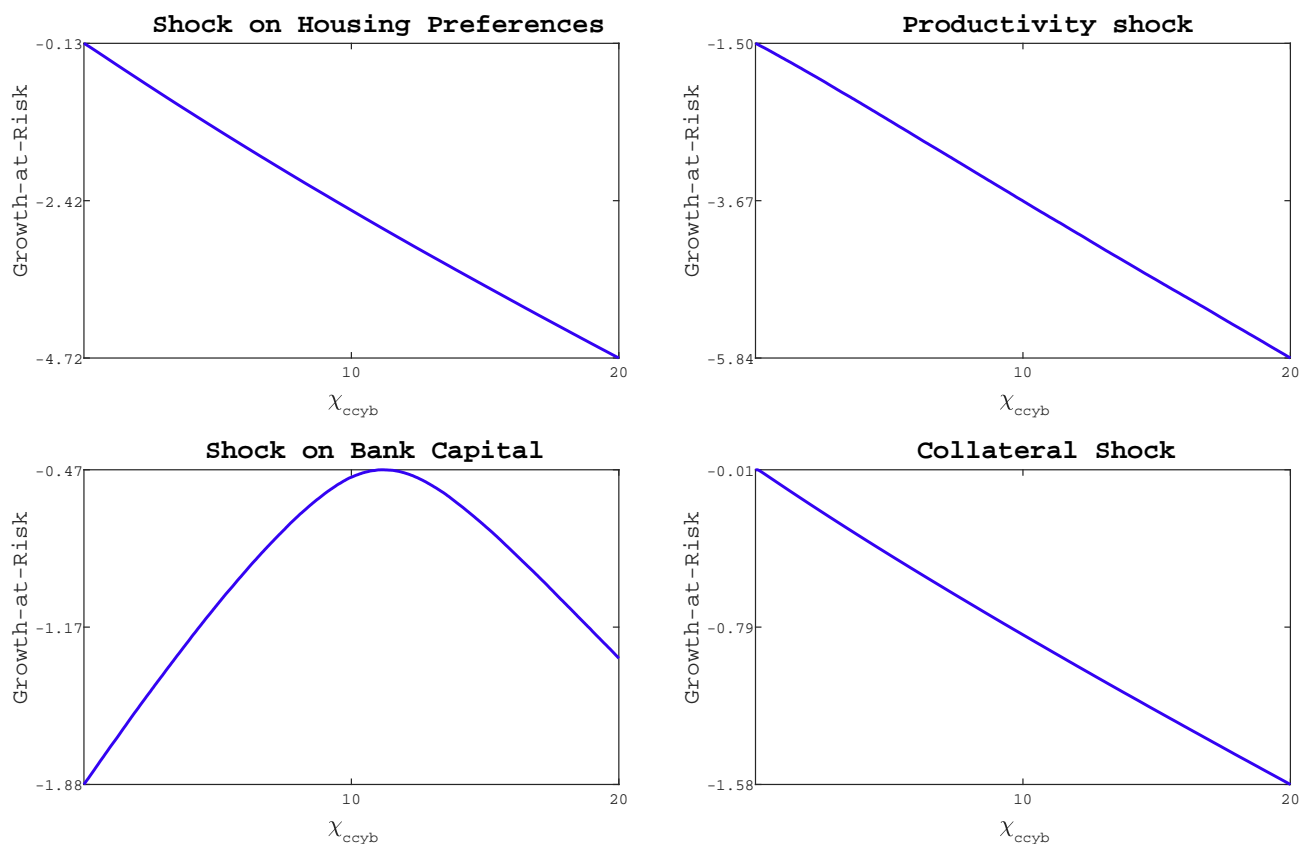

Note: Each plot represents the evolution of the 5th percentile of simulated distributions of annualized GDP growth as the reaction parameter in the CCyB rule, $\chi_{c c y b}$, evolves over $[0,20]$ in increments of 0.01. The policy parameters in the other policy rules remain constant $\left(\chi_{l t v}^{H}=\chi_{l t v}^{E}=-1.0, \chi_{\pi}=1.98\right.$, $\left.\chi_{Y}=0.34\right)$. The distribution of GDP growth is based on 1000 simulations of 200 periods for each shock scenario. Initial conditions are neutralized by excluding the first 100 periods.

Figure 12: Growth-at-risk conditional on LTV limits for households and firms
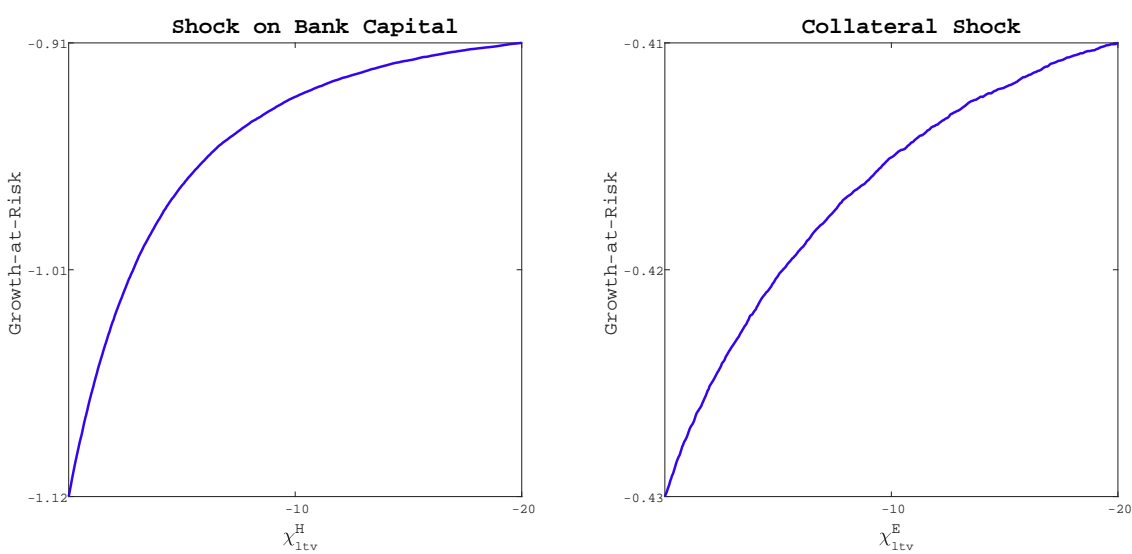

Note: The plot on the left represents the evolution of the 5th percentile of simulated distributions of annualized GDP growth as the reaction parameter $\chi_{l t v}^{H}$ in the corporate LTV rule evolves over $[-20,0]$ in increments of 0.01 in the case of a bank capital shock. The policy parameters in the other policy rules remain constant $\left(\chi_{l t v}^{E}=-1.0, \chi_{c c y b}=5.0, \chi_{\pi}=1.98, \chi_{Y}=0.34\right)$. The plot on the right represents the evolution of the $5 t h$ percentile of simulated distributions of annualized GDP growth as the reaction parameter $\chi_{l t v}^{E}$ in the mortgage LTV rule evolves over [-20,0] in increments of 0.01 , ceteris paribus. In both cases, the distributions of GDP growth are based on 1000 simulations of 200 periods. The initial conditions are neutralized by excluding the first 100 periods.

We first evaluate the spillovers of the $\mathrm{CCyB}$ on GaR, conditional on the four shocks considered so far. The results, represented in Figure 11, are essentially the same as those found when we consider 
the second moments of output. The worst-case GDP outcome worsens (i.e., GaR decreases) as the response to the Basel gap increases within the $\mathrm{CCyB}$ rule in all cases except one (bank capital shock). When the economy is faced with a bank capital shock, the CCyB makes the 5th percentile of GDP growth move rightward, provided that $\chi_{c c y b}$ is not too high. Hence, apart from this case, the CCyB conflicts with monetary policy regarding the objective of controlling extreme real risk.

Next, we investigate the possible side effects of mortgage and corporate LTV. We focus on the cases for which we had previously found clear-cut adverse side effects. The results are represented in Figure 12. Interestingly, we no longer find negative side effects for either the mortgage LTV in the case of a bank capital shock or the corporate LTV in the case of a collateral shock. ${ }^{25}$ This suggests that countercyclical LTV policies are likely to break the positive correlation between volatility and downside risk, which can be deduced from the literature on GaR. This means that these measures benefit the right tail of the distribution of GDP growth by opportunely making the upper quantiles less rigid over time. Therefore, these results confirm that LTV caps are unlikely to generate conflicts with the objectives with monetary policy.

\section{Concluding remarks}

Macroprudential policy has recently become a full-fledged instrument of economic policy, as demonstrated by the prompt relaxation of capital requirements in many countries in response to the COVID19 crisis. However, the widespread use of macroprudential tools raises the question of their interaction with monetary policy.

This paper offers an original approach to assessing the precise conditions under which macroprudential and monetary policies may be conflicting. These conditions are evaluated based on different types of shocks and different policy instruments, including countercyclical capital buffers (CCyBs) and loan-to-value (LTV) limits. Conflicts are identified when monetary policy has adverse side effects for macroprudential objectives and vice versa. Policy objectives refer not only to the usual volatilities of key variables but also to the probability of a financial crisis and growth-at-risk.

We find that conflicts are fairly frequent, especially in the case of technological and bank capital shocks, due to their widespread impact on the economy. Among the policy instruments, the CCyB and monetary policy are found to generate conflicts in many cases. They both "get in all the cracks" by widely impacting the economy through the adjustment of retail rates, albeit with targets often moving in opposite directions. Hence they work at cross-purposes. Nonetheless, a stronger reaction of monetary policy to the output gap should reduce the adverse side effects of monetary policy. In contrast, LTV caps, as more targeted instruments, cause few conflicts. Even when they are found to increase real-side volatility, they eventually reduce downside risks to GDP.

These results suggest that LTV limits can be easily implemented without worrying about potential spillovers. In contrast, the implementation of $\mathrm{CCyBs}$ and of monetary policy require smooth coordination.

Our results open the way for more formal analysis on the coordination of these policies and on the suitable institutional arrangements for the design of monetary and prudential regulation. Further research could focus on extending the analytical framework by inserting an endogenous risk-taking channel as an additional source of financial-side vulnerability caused by monetary policy. A second extension could embed explicit financial crises with feedback to real-side effects to further assess the real-side impact of macroprudential tools.

\footnotetext{
${ }^{25}$ From this point of view, we confirm the results found by Jensen et al. (2018).
} 


\section{References}

Adrian, T., Boyarchenko, N., and Giannone, D. (2019). Vulnerable growth. American Economic Review, 109(4):1263-1289.

Aikman, D., Giese, J., Kapadia, S., and McLeay, M. (2019). Targeting financial stability: Macroprudential or monetary policy? Working Paper Series 2278, European Central Bank.

Aiyara, S., Calomiris, C., and Wieladekc, T. (2016). How does credit supply respond to monetary policy and bank minimum capital requirements? European Economic Review, 82(C):142-165.

Ajello, A., Laubach, T., López-Salido, D., and Nakata, T. (2019). Financial stability and optimal interest rate policy. International Journal of Central Banking, 15(1):279-326.

Alam, Z., Adrian, A., Eiseman, J., Gelos, R., Kang, H., Narita, M., Nier, E., and Wang, N. (2019). Digging deeper - Evidence on the effects of macroprudential policies from a new database. IMF WP/19/66, International Monetary Fund.

Alpanda, S. and Zubairy, S. (2017). Addressing household indebtedness: Monetary, fiscal or macroprudential policy? European Economic Review, 92:47-73.

Altunbas, Y., Binici, M., and Gambacorta, L. (2018). Macroprudential policy and bank risk. Journal of International Money and Finance, 81:203-220.

Angelini, P., Neri, S., and Panetta, F. (2014). The interaction between capital requirements and monetary policy. Journal of Money, Credit and Banking, 46(6):1073-1112.

Basel Committee on Banking Supervision (2019). The Basel Framework - Leverage Ratio. Technical report, The Basel Committee.

Benes, J. and Kumhof, M. (2015). Risky bank lending and countercyclical capital buffers. Journal of Economic Dynamics and Control, 58:58 - 80.

Benigno, G., Foerster, A., Otrok, C., and Rebucci, A. (2020). Estimating macroeconomic models of financial crises: An endogenous regime switching approach. NBER Working Papers 26935, National Bureau of Economic Research, Inc.

Bianchi, J. and Mendoza, E. (2018). Optimal time-consistent macroprudential policy. Journal of Political Economy, 126(2):588-634.

Bodenstein, M., Guerrieri, L., and LaBriola, J. (2019). Macroeconomic policy games. Journal of Monetary Economics, 101(C):64-81.

Brunnermeier, M. and Sannikov, Y. (2014). A macroeconomic model with a financial sector. American Economic Review, 104(2):379-421.

Bruno, V., Shim, I., and Shin, H. S. (2017). Comparative assessment of macroprudential policies. Journal of Financial Stability, 28:183-202.

Burlon, L., Gerali, A., Notarpietro, A., and Pisani, M. (2018). Non-standard monetary policy, asset prices and macroprudential policy in a monetary union. Journal of International Money and Finance, 88(C):25-53. 
Cerutti, E., Claessens, S., and Laeven, L. (2017). The use and effectiveness of macroprudential policies: New evidence. Journal of Financial Stability, 28:203 - 224.

Chen, J. and Columba, F. (2016). Macroprudential and monetary policies interactions in a DSGE model for Sweden. IMF Working Paper, (16/74).

Claessens, S., Ghosh, S. R., and Mihet, R. (2013). Macro-prudential policies to mitigate financial system vulnerabilities. Journal of International Money and Finance, 39:153-185.

Collard, F., Dellas, H., Diba, B., and Loisel, O. (2017). Optimal Monetary and Prudential Policies. American Economic Journal: Macroeconomics, 9(1):40-87.

Colletaz, G., Levieuge, G., and Popescu, A. (2018). Monetary policy and long-run systemic risk-taking. Journal of Economic Dynamics and Control, 86:165-184.

De Jonghe, O., Dewachter, H., and Ongena, S. (2020). Bank capital (requirements) and credit supply: Evidence from pillar 2 decisions. Journal of Corporate Finance, 60:101518.

De Paoli, B. and Paustian, M. (2017). Coordinating monetary and macroprudential policies. Journal of Money, Credit and Banking, 49(2-3):319-349.

Dupor, B. (2005). Stabilizing non-fundamental asset price movements under discretion and limited information. Journal of Monetary Economics, 52(4):727-747.

Farhi, E. and Tirole, J. (2012). Collective moral hazard, maturity mismatch, and systemic bailouts. American Economic Review, 102(1):60-93.

Farhi, E. and Werning, I. (2016). A theory of macroprudential policies in the presence of nominal rigidities. Econometrica, 84:1645-1704.

Fender, I. and Lewrick, U. (2015). Calibrating the leverage ratio. BIS Quarterly Review.

Fraisse, H., Lé, M., and Thesmar, D. (2020). The real effects of bank capital requirements. Management Science, 66(1):5-23.

Gambacorta, L. and Karmakar, S. (2018). Leverage and risk-weighted capital requirements. International Journal of Central Banking, 14(5):153-191.

Gambacorta, L. and Murcia, A. (2020). The impact of macroprudential policies in Latin America: An empirical analysis using credit registry data. Journal of Financial Intermediation, (Forthcoming).

Garcia Revelo, J., Lucotte, Y., and Pradines-Jobet, F. (2020). Macroprudential and monetary policies: The need to dance the tango in harmony. Journal of International Money and Finance, (Forthcoming).

Gelain, P. and Ilbas, P. (2017). Monetary and macroprudential policies in an estimated model with financial intermediation. Journal of Economic Dynamics and Control, 78:164 - 189.

Gerali, A., Neri, S., Sessa, L., and Signoretti, F. (2010). Credit and banking in a DSGE model of the euro area. Journal of Money, Credit and Banking, 42(s1):107-141.

Gersbach, H. and Rochet, J.-C. (2017). Capital regulation and credit fluctuations. Journal of Monetary Economics, 90(C):113-124. 
Gropp, R., Mosk, T., Ongena, S., and Wix, C. (2018). Banks response to higher capital requirements: Evidence from a quasi-natural experiment. The Review of Financial Studies, 32(1):266-299.

Holmstrom, B. and Tirole, J. (1997). Financial intermediation, loanable funds, and the real sector. The Quarterly Journal of Economics, 112(3):663-691.

Iacoviello, M. (2005). House prices, borrowing constraints, and monetary policy in the business cycle. American economic review, 95(3):739-764.

Iacoviello, M. (2015). Financial business cycles. Review of Economic Dynamics, 18(1):140-164.

Iacoviello, M. and Neri, S. (2010). Housing market spillovers: Evidence from an estimated DSGE model. American Economic Journal: Macroeconomics, 2(2):125-164.

Jensen, H., Ravn, S., and Santoro, E. (2018). Changing credit limits, changing business cycles. European Economic Review, 102(C):211-239.

Jimenez, G., Ongena, S., Peydro, J.-L., and Saurina, J. (2014). Hazardous times for monetary policy: What do twenty-three million bank loans say about the effects of monetary policy on credit risktaking? Econometrica, 82(2):463-505.

Juelsrud, R. and Wold, E. (2020). Risk-weighted capital requirements and portfolio rebalancing. Journal of Financial Intermediation, 41:100806.

Kashyap, A. and Siegert, C. (2020). Financial stability considerations and monetary policy. International Journal of Central Banking, 16(1):231-266.

Kim, S. and Mehrotra, A. (2018). Effects of monetary and macroprudential policies - Evidence from four inflation targeting economies. Journal of Money, Credit and Banking, 50(5):967-992.

Korinek, A. and Simsek, A. (2016). Liquidity trap and excessive leverage. American Economic Review, 106(3):699-738.

Lambertini, L., Mendicino, C., and Teresa Punzi, M. (2013). Leaning against boom-bust cycles in credit and housing prices. Journal of Economic Dynamics and Control, 37(8):1500-1522.

Lazopoulos, I. and Gabriel, V. (2019). Policy mandates and institutional architecture. Journal of Banking \& Finance, 100(C):122-134.

Lozej, M., Onorante, L., and Rannenberg, A. (2018). Countercyclical capital regulation in a small open economy DSGE model. Working Paper Series 2144, European Central Bank.

Mendicino, C., Nikolov, K., Suarez, J., and Supera, D. (2018). Optimal dynamic capital requirements. Journal of Money, Credit and Banking, 50(6):1271-1297.

Richter, B., Schularick, M., and Shim, I. (2018). The macroeconomic effects of macroprudential policy. BIS Working Papers 740, Bank for International Settlements.

Rubio, M. and Carrasco-Gallego, J. (2014). Macroprudential and monetary policies: Implications for financial stability and welfare. Journal of Banking and Finance, 49:326 - 336.

Rubio, M. and Yao, F. (2020). Macroprudential policies in a low interest rate environment. Journal of Money, Credit and Banking, (Forthcoming). 
Silvo, A. (2019). The interaction of monetary policy and macroprudential policies. Journal of Money, Credit and Banking, 51:859-894.

Stein, J. (2013). Overheating in credit markets: Origins, measurement, and policy responses. In Speech at the Federal Reserve Bank of St. Louis. February 7.

Vandenbussche, J., Vogel, U., and Detragiache, E. (2015). Macroprudential policies and housing prices: A new database and empirical evidence for Central, Eastern, and Southeastern Europe. Journal of Money, Credit and Banking, 47(S1):343-377. 


\section{A The rest of the model}

\section{Employment agencies}

Workers provide differentiated labour types sold by unions to perfectly competitive employment agencies, which assemble them in a CES aggregator with stochastic parameter $\varepsilon_{t}^{l}$ and sell homogeneous labour to entrepreneurs. For each labour type $m$, there are two unions, one for patient households and one for impatient households. Each union sets nominal wages $W_{t}^{i}(m)$ for its members, with $i \in\{P, I\}$, by maximizing their utility subject to downward-sloping demand and to quadratic adjustment costs (parameterized by $\kappa_{w}$ ), with indexation $\iota_{w}$ to lagged inflation and $\left(1-\iota_{w}\right)$ to steady-state inflation (denoted $\pi$ ). Unions charge their members lump-sum fees to cover adjustment costs with equal split. Hence, they seek to maximize the following expression:

$$
\mathrm{E}_{0} \sum_{t=0}^{\infty} \beta_{i}^{t}\left\{U_{c_{t}^{i}}(j, m)\left[\frac{W_{t}^{i}(m)}{P_{t}} l_{t}^{i}(j, m)-\frac{\kappa_{w}}{2}\left(\frac{W_{t}^{i}(m)}{W_{t-1}^{i}(m)}-\pi_{t-1}^{\iota-1} \pi^{1-\iota_{w}}\right)^{2} \frac{W_{t}^{i}}{P_{t}}\right]-\frac{l_{t}^{i}(j, m)^{1+\phi}}{1+\phi}\right\},
$$

subject to demand from employment agencies

$$
l_{t}^{i}(i, m)=l_{t}^{i}(m)=\left(\frac{W_{t}^{i}(m)}{W_{t}^{i}}\right)^{-\varepsilon^{l}} l_{t}^{i},
$$

with $\varepsilon^{l}$ being the elasticity of labour demand.

\section{Capital and final goods producers}

Capital-producing firms act in a perfectly competitive market. They are owned by the entrepreneurs. They purchase last period's undepreciated capital $(1-\delta) k_{t-1}$ from the entrepreneurs at a price $Q_{t}^{k}$ and $i_{t}$ units of final goods from retail firms at a price $P_{t}$. They combine them to produce new capital. The transformation of the final goods into capital is subject to quadratic adjustment costs. The new capital is then sold back to the entrepreneurs at the same price $Q_{t}^{k}$. Hence, capital producers maximize their expected discounted profits:

$$
\max _{\left\{k_{t}(j), i_{t}(j)\right\}} \mathrm{E}_{0} \sum_{t=0}^{\infty} \Lambda_{0, t}^{e}\left(q_{t}^{k}\left[k_{t}(j)-(1-\delta) k_{t-1}(j)\right]-i_{t}(j)\right)
$$

subject to

$$
k_{t}(j)=(1-\delta) k_{t-1}(j)+\left[1-\frac{\kappa_{i}}{2}\left(\frac{i_{t}(j)}{i_{t-1}(j)}-1\right)^{2}\right] i_{t}(j)
$$

where $\kappa_{i}$ denotes the cost of adjusting investment, $\varepsilon_{q k}$ is an investment shock, $q_{t}^{k}=Q_{t}^{k} / P_{t}$ is the real price of capital, and $\Lambda_{0, t}^{e}$ is the entrepreneurs' discount factor.

Final good producers are owned by patient households. They act in monopolistic competition, and their prices are sticky because of the existence of quadratic adjustment costs when prices are revised. They purchase the intermediate (wholesale) good from entrepreneurs in a competitive market and then slightly differentiate it at no additional cost. Each firm $j$ chooses its price to maximize the expected 
discounted value of profits:

$$
\max _{\left\{P_{t}(j)\right\}} \mathrm{E}_{0} \sum_{t=0}^{\infty} \Lambda_{0, t}^{P}\left[\left(P_{t}(j)-P_{t}^{W}\right) y_{t}(j)-\frac{\kappa_{P}}{2}\left(\frac{P_{t}(j)}{P_{t-1}(j)}-\pi_{t-1}^{\iota_{p}} \pi^{1-\iota_{p}}\right)^{2} P_{t} y_{t}\right]
$$

subject to the demand derived from consumers' maximization

$$
y_{t}(j)=\left(\frac{P_{t}(j)}{P_{t}}\right)^{-\varepsilon^{y}} y_{t}
$$

where $\kappa_{p}$ denotes the cost of adjusting prices, $\iota_{p} \in[0,1]$ is the degree of indexation to past inflation, $\varepsilon^{y}$ is the demand price elasticity, $P_{t}^{W}$ is the wholesale price and $\Lambda_{0, t}^{P}$ is the patient households' discount factor.

\section{Market clearing and stochastic processes}

The market clearing conditions for the final goods market are given by $y_{t}=c_{t}+q_{t}^{k}\left[k_{t}-(1-\delta) k_{t-1}\right]$, with $c_{t}=c_{t}^{P}+c_{t}^{I}+c_{t}^{E}$. Equilibrium in the housing market is given by $\bar{h}=h_{t}^{P}(i)+h_{t}^{I}(i)$, where $\bar{h}$ is the exogenous fixed housing supply. With the exception of monetary policy shocks, the exogenous variables follow an $A R(1)$ process such that $\log \left(\varepsilon_{t}^{x}\right)=\left(1-\rho_{x}\right) \log \left(\varepsilon^{x}\right)+\rho^{x} \log \left(\varepsilon_{t-1}^{x}\right)+\xi_{t}^{x}$, with $x=\{h, a, K b, m\}$, where $\xi_{t}^{x} \sim$ i.i.d. $\mathcal{N}\left(0, \sigma_{x}^{2}\right)$. 


\section{B Equilibrium conditions}

This part of the appendix reports the first-order conditions for the agents (optimizing problems and the other relationships that define the equilibrium of the model). The variables $\lambda_{t+j}^{x}, \forall x=\{I, P, E\}$ and $j=\{0,1\}, s_{t}^{I}$ and $s_{t}^{E}$ are Lagrange multipliers. $\mathcal{P}_{t}^{R}$ and $\mathcal{P}_{t}^{b}$ represent the profits of final good producers and banks in $t$, respectively. Note that $L^{i}\left(x_{t}\right)=x_{t-i}$ and $F^{i}\left(x_{t}\right)=\mathrm{E}_{t}\left(x_{t+i}\right), \forall x_{t}$. Finally, a variable without a time subscript designates steady-state value.

\section{B.1 Patient households}

$$
\begin{gathered}
c_{t}^{P}+q_{t}^{h}\left(h_{t}^{P}-h_{t-1}^{P}\right)+d_{t}^{P}=w_{t}^{P} l_{t}^{P}+\left(1+r_{t-1}^{d}\right) d_{t-1}^{P} / \pi_{t}+t_{t}^{P} \\
\frac{1-a^{p}}{c_{t}^{p}-a^{p} c_{t-1}^{p}}=\lambda_{t}^{p} \\
\lambda_{t}^{P} q_{t}^{h}=\frac{\varepsilon_{t}^{h}}{h_{t}^{P}}+\beta_{P} \mathrm{E}_{t}\left(\lambda_{t+1}^{P} q_{t+1}^{h}\right) \\
\lambda_{t}^{P}=\beta_{P} \mathrm{E}_{t}\left[\lambda_{t+1}^{P} \frac{\left(1+r_{t}^{d}\right)}{\pi_{t+1}}\right]
\end{gathered}
$$

\section{B.2 Impatient Households}

$$
\begin{gathered}
c_{t}^{I}+q_{t}^{h}\left(h_{t}^{I}-h_{t-1}^{I}\right)+\left(1+r_{t-1}^{b H}\right) b_{t-1}^{I} / \pi_{t}=w_{t}^{I} l_{t}^{I}+b_{t}^{H}+t_{t}^{I} \\
\left(1+r_{t}^{b H}\right) b_{t}^{H} \leq L T V_{t}^{H} E_{t}\left[q_{t+1}^{h} h_{t}^{I} \pi_{t+1}\right] \varepsilon_{t}^{m} \\
\frac{1-a^{I}}{c_{t}^{I}-a^{I} c_{t-1}^{I}}=\lambda_{t}^{I} \\
\lambda_{t}^{I} q_{t}^{h}=\frac{\varepsilon_{t}^{h}}{h_{t}^{I}}+\beta_{I} \mathrm{E}_{t}\left[\lambda_{t+1}^{I} q_{t+1}^{h}\right]+\beta_{I} \mathrm{E}_{t}\left[s_{t}^{I} L T V_{t}^{H} q_{t+1}^{h} \pi_{t+1}\right] \varepsilon_{t}^{m} \\
\lambda_{t}^{I}=\beta_{I} \mathrm{E}_{t}\left[\lambda_{t+1}^{I} \frac{\left(1+R_{t}^{b h}\right)}{\pi_{t+1}}\right]+s_{t}^{I}\left(1+r_{t}^{b h}\right)
\end{gathered}
$$

\section{B.3 Entrepreneurs}

$$
\begin{gathered}
c_{t}^{E}+w_{t}^{P} l_{t}^{E, P}+w_{t}^{I} l_{t}^{E, I}+\left(1+r_{t-1}^{b E}\right) b_{t-1}^{E} / \pi_{t}+q_{t}^{k} k_{t}^{E}=\frac{y_{t}^{E}}{x_{t}}+b_{t}^{E}+q_{t}^{k}(1-\delta) k_{t-1}^{E} \\
\left(1+r_{t}^{b E}\right) b_{t}^{E} \leq L T V_{t}^{E} E_{t}\left[q_{t+1}^{k} k_{t}^{E} \pi_{t+1}(1-\delta)\right] \\
\frac{1-a^{E}}{c_{t}^{E}-a^{E} c_{t-1}^{E}}=\lambda_{t}^{E} \\
\lambda_{t}^{E}=\beta_{E} \mathrm{E}_{t}\left[\lambda_{t+1}^{E} \frac{\left(1+r_{t}^{b E}\right)}{\pi_{t+1}}\right]+s_{t}^{I}\left(1+r_{t}^{b E}\right)
\end{gathered}
$$




$$
\begin{gathered}
\lambda_{t}^{E} q_{t}^{k}=\beta_{E} \mathrm{E}_{t} \lambda_{t+1}^{E}\left[r_{t+1}^{k}+q_{t+1}^{k}(1-\delta)\right] \\
+\mathrm{E}_{t}\left[s_{t}^{E} L T V_{t}^{E} q_{t+1}^{k} \pi_{t+1}(1-\delta)\right] \\
y_{t}^{E}=\varepsilon_{t}^{a}\left[k_{t-1}^{E}\right]^{\alpha}\left[\left(l_{t}^{E, P}\right)^{\mu}\left(l_{t}^{E, I}\right)^{1-\mu}\right]^{1-\alpha} \\
w_{t}^{P}=\mu(1-\alpha) \frac{y_{t}^{E}}{l_{t}^{E, P}} \frac{1}{x_{t}} \\
w_{t}^{I}=(1-\mu)(1-\alpha) \frac{y_{t}^{E}}{l_{t}^{E, I}} \frac{1}{x_{t}} \\
r_{t}^{k}=\alpha \frac{y_{t}^{E}}{k_{t-1}^{E}} \frac{1}{x_{t}}
\end{gathered}
$$

\section{B.4 Capital Goods Producers}

$$
\begin{gathered}
k_{t}=(1-\delta) k_{t-1}+\left[1-\frac{k_{i}}{2}\left(\frac{i_{t}}{i_{t-1}}-1\right)^{2}\right] i_{t} \\
1=q_{t}^{k}\left[1-\frac{k_{i}}{2}\left(\frac{i_{t}}{i_{t-1}}-1\right)^{2}-k_{i}\left(\frac{i_{t}}{i_{t-1}}-1\right) \frac{i_{t}}{i_{t-1}}\right] \\
+\beta_{E} E_{t}\left[\frac{\lambda_{t+1}^{E}}{\lambda_{t}^{E}} q_{t+1}^{k} \varepsilon_{t+1}^{q k} k_{i}\left(\frac{i_{t+1} \varepsilon_{t+1}^{q k}}{i_{t}}-1\right) \varepsilon_{t+1}^{q k}\left(\frac{i_{t+1}}{i_{t}}\right)^{2}\right]
\end{gathered}
$$

\section{B.5 Final Goods Producers}

$$
\begin{gathered}
\mathcal{P}_{t}^{R}=y_{t}\left(1-\frac{1}{x_{t}}\right)-\frac{k_{P}}{2}\left(\pi_{t}-\pi_{t-1}^{l_{P}} \bar{\pi}^{1-t_{P}}\right)^{2} \\
1-\varepsilon^{y}+\frac{\varepsilon^{y}}{x_{t}}-k_{P}\left(\pi_{t}-\pi_{t-1}^{t_{P}} \bar{\pi}^{1-t_{P}}\right) \pi_{t} \\
+\beta_{P} E_{t}\left[\frac{\lambda_{t+1}^{P}}{\lambda_{t}^{P}} k_{P}\left(\pi_{t+1}-\pi_{t}^{t_{P}} \bar{\pi}^{1-t_{P}}\right) \pi_{t+1} \frac{y_{t+1}}{y_{t}}\right]=0
\end{gathered}
$$

\section{B.6 Labour unions}

\section{Patient households}

$$
\begin{aligned}
k_{w}\left(\pi_{t}^{w P}-\pi_{t-1}^{\iota_{w}} \bar{\pi}^{1-\iota_{w}}\right) \pi_{t}^{w P}= & \beta_{P} E_{t}\left[\frac{\lambda_{t+1}^{P}}{\lambda_{t}^{P}} k_{w}\left(\pi_{t+1}^{w P}-\pi_{t}^{\iota_{w}} \bar{\pi}^{1-\iota_{w}}\right) \frac{\left(\pi_{t+1}^{w P}\right)^{2}}{\pi_{t+1}}\right] \\
& +\left(1-\varepsilon^{l}\right) l_{t}^{P}+\frac{\varepsilon^{l}\left(l_{t}^{P}\right)^{1+\phi}}{w_{t}^{w P} \lambda_{t}^{P}} \\
& \pi_{t}^{w P}=\frac{w_{t}^{w P}}{w_{t-1}^{w P}} \pi_{t}
\end{aligned}
$$


Impatient households

$$
\begin{aligned}
k_{w}\left(\pi_{t}^{w I}-\pi_{t-1}^{\iota_{w}} \bar{\pi}^{1-\iota_{w}}\right) \pi_{t}^{w I}= & \beta_{I} E_{t}\left[\frac{\lambda_{t+1}^{I}}{\lambda_{t}^{I}} k_{w}\left(\pi_{t+1}^{w I}-\pi_{t}^{\iota_{w}} \bar{\pi}^{1-\iota_{w}}\right) \frac{\left(\pi_{t+1}^{w I}\right)^{2}}{\pi_{t+1}}\right] \\
& +\left(1-\varepsilon^{l}\right) l_{t}^{I}+\frac{\varepsilon^{l}\left(l_{t}^{I}\right)^{1+\phi}}{w_{t}^{w I} \lambda_{t}^{I}} \\
& \pi_{t}^{w I}=\frac{w_{t}^{w I}}{w_{t-1}^{w I}} \pi_{t}
\end{aligned}
$$

\section{B.7 Banks}

\section{Wholesale unit}

$$
\begin{aligned}
& R_{t}^{b H}=R_{t}-\kappa_{c a r}\left(\frac{K_{t}^{b}}{\omega_{t}^{E} B_{t}^{E}+\omega_{t}^{H} B_{t}^{H}}-v_{t}\right)\left(\frac{K_{t}^{b}}{\omega_{t}^{E} B_{t}^{E}+\omega_{t}^{H} B_{t}^{H}}\right)^{2} \omega_{t}^{H} \\
& -\kappa_{\text {lev }}\left(\frac{K_{t}^{b}}{B_{t}^{E}+B_{t}^{H}}-l e v\right)\left(\frac{K_{t}^{b}}{B_{t}^{E}+B_{t}^{H}}\right)^{2} \\
& R_{t}^{b E}=R_{t}-\kappa_{c a r}\left(\frac{K_{t}^{b}}{\omega_{t}^{E} B_{t}^{E}+\omega_{t}^{H} B_{t}^{H}}-v_{t}\right)\left(\frac{K_{t}^{b}}{\omega_{t}^{E} B_{t}^{E}+\omega_{t}^{H} B_{t}^{H}}\right)^{2} \omega_{t}^{E} \\
& -\kappa_{\text {lev }}\left(\frac{K_{t}^{b}}{B_{t}^{E}+B_{t}^{H}}-l e v\right)\left(\frac{K_{t}^{b}}{B_{t}^{E}+B_{t}^{H}}\right)^{2} \\
& K_{t}^{b}=\left(1-\delta^{b}\right) \frac{K_{t-1}^{b}}{\varepsilon_{t}^{K b}}+\mathcal{P}_{t-1}^{b} \\
& B_{t}^{H}+B_{t}^{E}=D_{t}+K_{t}^{b} \\
& \omega_{t}^{H}=\left(1-\rho_{H}\right) \bar{w}^{H}+\left(1-\rho_{H}\right) \chi_{H}\left(Y_{t}-Y_{t-4}\right)+\rho_{H} \omega_{t-1}^{H} \\
& \omega_{t}^{E}=\left(1-\rho_{E}\right) \bar{w}^{E}+\left(1-\rho_{E}\right) \chi_{E}\left(Y_{t}-Y_{t-4}\right)+\rho_{E} \omega_{t-1}^{E} \\
& \mathcal{P}_{t}^{b}=r_{t}^{b H} b_{t}^{H}+r_{t}^{b E} b_{t}^{E}-r_{t}^{d} d_{t}-\mathcal{D}_{t}^{v}\left(K_{t}^{b}\right)-\mathcal{D}_{t}^{l e v}\left(K_{t}^{b}\right)-\sum_{s=H, E} \mathcal{A}_{b s}\left(r_{t}^{b s}\right)-\mathcal{A}_{d}\left(r_{t}^{d}\right) \\
& \mathcal{D}_{t}^{v}\left(K_{t}^{b}\right)=\frac{\kappa_{c a r}}{2}\left(\frac{K_{t}^{b}}{\omega_{t}^{E} B_{t}^{E}+\omega_{t}^{H} B_{t}^{H}}-v_{t}\right)^{2} K_{t}^{b} \\
& \mathcal{D}_{t}^{l e v}\left(K_{t}^{b}\right)=\frac{\kappa_{l e v}}{2}\left(\frac{K_{t}^{b}}{B_{t}^{E}+B_{t}^{H}}-l e v\right)^{2} K_{t}^{b} \\
& \mathcal{A}_{b s}\left(r_{t}^{b s}\right) \equiv \frac{\kappa_{b s}}{2}\left(\frac{r_{t}^{b s}}{r_{t-1}^{b s}}-1\right)^{2} r_{t}^{b s} b_{t}^{s}, \quad \text { with } s=\{H, E\} \\
& \mathcal{A}_{d}\left(r_{t}^{d}\right) \equiv \frac{\kappa_{d}}{2}\left(\frac{r_{t}^{d}}{r_{t-1}^{d}}-1\right)^{2} r_{t}^{d} d_{t}
\end{aligned}
$$




\section{Retail units}

$$
\begin{aligned}
\left(\frac{\varepsilon^{d}}{\varepsilon^{d}-1}\right) \frac{R_{t}^{d}}{r_{t}^{d}}= & \left(\frac{\varepsilon^{d}}{\varepsilon^{d}-1}\right)-1-\kappa_{d}\left(\frac{r_{t}^{d}}{r_{t-1}^{d}}-1\right) \frac{r_{t}^{d}}{r_{t-1}^{d}} \\
& +\beta_{P} E_{t}\left[\frac{\lambda_{t+1}^{P}}{\lambda_{t}^{P}} \kappa_{d}\left(\frac{r_{t+1}^{d}}{r_{t}^{d}}-1\right)\left(\frac{r_{t+1}^{d}}{r_{t}^{d}}\right)^{2} \frac{d_{t+1}^{P}}{d_{t}^{P}}\right] \\
\left(\frac{\varepsilon^{b s}}{\varepsilon^{b s}-1}\right) \frac{R_{t}^{b s}}{r_{t}^{b s}} & =\left(\frac{\varepsilon^{b s}}{\varepsilon^{b s}-1}\right)-1+\kappa_{b s}\left(\frac{r_{t}^{b s}}{r_{t-1}^{b s}}-1\right) \frac{r_{t}^{b s}}{r_{t-1}^{b s}} \\
& -\beta_{P} E_{t}\left[\frac{\lambda_{t+1}^{P}}{\lambda_{t}^{P}} \kappa_{b s}\left(\frac{r_{t+1}^{b s}}{r_{t}^{b s}}-1\right)\left(\frac{r_{t+1}^{b s}}{r_{t}^{b s}}\right)^{2} \frac{b_{t+1}^{s}}{b_{t}^{s}}\right],
\end{aligned}
$$

with $s=\{H, E\}$

\section{B.8 Monetary policy and macroprudential policy}

$$
\begin{aligned}
& \frac{1+r_{t}}{1+r}=\left(\frac{1+r_{t-1}}{1+r}\right)^{\rho_{r}}\left(\frac{\pi_{t}}{\pi}\right)^{\chi_{\pi}\left(1-\rho_{r}\right)}\left(\widetilde{Y}_{t}\right)^{\chi_{y}\left(1-\rho_{r}\right)} \varepsilon_{t}^{r} \\
& v_{t}=\left(v_{t-1}\right)^{\rho_{v}}\left[v\left(\frac{\widetilde{B_{t}}}{Y_{t}}\right)^{\chi_{c c y b}}\right]^{\left(1-\rho_{v}\right)} \\
& L T V_{t}^{s}=\left(L T V_{t-1}^{s}\right)^{\rho_{l t v}^{s}}\left(L T V^{s}\left(\frac{\widetilde{B_{t}^{s}}}{Y_{t}}\right)^{\chi_{l t v}^{s}}\right)^{\left(1-\rho_{l t v}^{s}\right)}, \text { with } s \in\{H, E\} \\
& \widetilde{Y}_{t}+\lambda_{H P}(1-L)^{2}(1-F)^{2} \widetilde{Y}_{t}=\lambda_{H P}(1-L)^{2}(1-F)^{2} Y_{t} \\
& \left(\frac{\widetilde{B_{t}}}{Y_{t}}\right)+\lambda_{H P}(1-L)^{2}(1-F)^{2}\left(\frac{\widetilde{B_{t}}}{Y_{t}}\right)=\lambda_{H P}(1-L)^{2}(1-F)^{2}\left(\frac{B_{t}}{Y_{t}}\right) \\
& \left(\widetilde{B_{t}^{i}} \frac{\lambda_{t}}{Y_{t}}(1-L)^{2}(1-F)^{2}\left(\frac{\widetilde{B_{t}^{i}}}{Y_{t}}\right)=\lambda_{H P}(1-L)^{2}(1-F)^{2}\left(\frac{B_{t}^{i}}{Y_{t}}\right)\right.
\end{aligned}
$$

\section{B.9 Market clearing conditions}

$Y_{t}=c_{t}^{P}+c_{t}^{I}+c_{t}^{E}+k_{t}-(1-\delta) k_{t-1}, \quad y_{t}^{E}=y_{t}, \quad l_{t}^{E, P}=l_{t}^{P}, \quad l_{t}^{E, I}=l_{t}^{I}, \quad 1=h_{t}^{P}+h_{t}^{I}, \quad b_{t}^{E}=B_{t}^{E}$, $b_{t}^{H}=B_{t}^{H}, \quad B_{t}=B_{t}^{E}+B_{t}^{H}, \quad d_{t}^{P}=D_{t}, \quad k_{t}^{E}=K_{t}$.

\section{B.10 Shocks}

$$
\begin{aligned}
& \log \left(\varepsilon_{t}^{x}\right)=\left(1-\rho_{x}\right) \log \left(\varepsilon^{x}\right)+\rho^{x} \log \left(\varepsilon_{t-1}^{x}\right)+\xi_{t}^{x}, \text { with } x=\{h, a, K b, m\} \\
& \text { and } \xi_{t}^{x} \sim \text { i.i.d. } \mathcal{N}\left(0, \sigma_{x}^{2}\right) .
\end{aligned}
$$

\section{B.11 Crisis probability}

$$
\mathcal{P}_{t}^{c}=\frac{\exp \left(\mathcal{C}+h_{1}\left(\frac{\widetilde{B_{t}}}{Y_{t}}\right)+h_{2}\left(\frac{K_{t}^{b}}{B_{t}}-l e v\right)\right)}{1+\exp \left(\mathcal{C}+h_{1}\left(\frac{\widetilde{B_{t}}}{Y_{t}}\right)+h_{2}\left(\frac{K_{t}^{b}}{B_{t}}-l e v\right)\right)} \times 100
$$




\section{The leverage ratio and its link with the capital adequacy ratio}

In line with Basel III, we assume that banks have to meet a regulatory leverage ratio. In practice, this measure is intended to restrict the buildup of leverage in the banking sector to avoid fast deleveraging processes that can damage the broader financial system and the real economy. In addition, it reinforces and backstops the risk-based capital requirements with a simple, non-risk-based measure. ${ }^{26}$ In the model, any deviation from the regulatory level, denoted lev, implies a quadratic cost parameterized by $\kappa_{\text {lev }}$, proportional to outstanding bank capital, such that:

$$
\mathcal{D}_{t}^{l e v}\left(K_{t}^{b}(j)\right) \equiv \frac{\kappa_{l e v}}{2}\left(\frac{K_{t}^{b}(j)}{B_{t}^{E}(j)+B_{t}^{H}(j)}-l e v\right)^{2} K_{t}^{b}(j)
$$

A 3\% minimum leverage ratio, as required by the Basel III framework, is incompatible with the capital adequacy ratio in the steady state of our model due to the relative simplicity of the financial sector. For example, exposure related to interbank loans, government bonds, derivatives, securities financing transactions and off-balance sheet items are not considered here. Hence, we follow Fender and Lewrick (2015), who propose a convenient method to calibrate a leverage ratio in a manner consistent with the capital adequacy ratio. By expanding the definition of the leverage ratio, we obtain:

$$
\begin{aligned}
l e v & =\frac{K_{t}^{b}(j)}{B_{t}^{H}(j)+B_{t}^{E}(j)} \\
& =\frac{K_{t}^{b}(j)}{\omega_{t}^{H} B_{t}^{H}(j)+\omega_{t}^{E} B_{t}^{E}(j)} \times \frac{\omega_{t}^{H} B_{t}^{H}(j)+\omega_{t}^{E} B_{t}^{E}(j)}{B_{t}^{H}(j)+B_{t}^{E}(j)} \\
& \equiv C A R \times D R
\end{aligned}
$$

where $D R$ is the so-called density ratio, defined as the ratio of risk-weighted assets to the leverage ratio exposure measure. Thus, we calibrate lev so that eq. C2 is satisfied, ensuring a steady-state consistent calibration.

\footnotetext{
${ }^{26}$ See Basel Committee on Banking Supervision (2019) for an extended explanation of the definition, measurement and composition of the leverage ratio.
} 


\section{Loan-to-value and countercyclical capital buffer in practice}

Figure D1: Loan-to-value restriction and countercyclical capital buffer requirements in Europe

Loan-to-Value (EU)

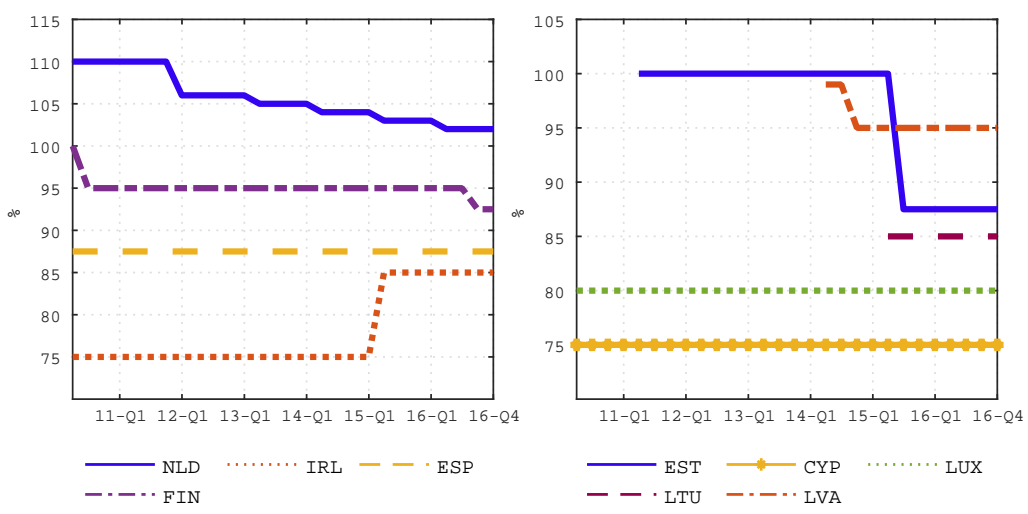

\section{CCyB (Europe)}
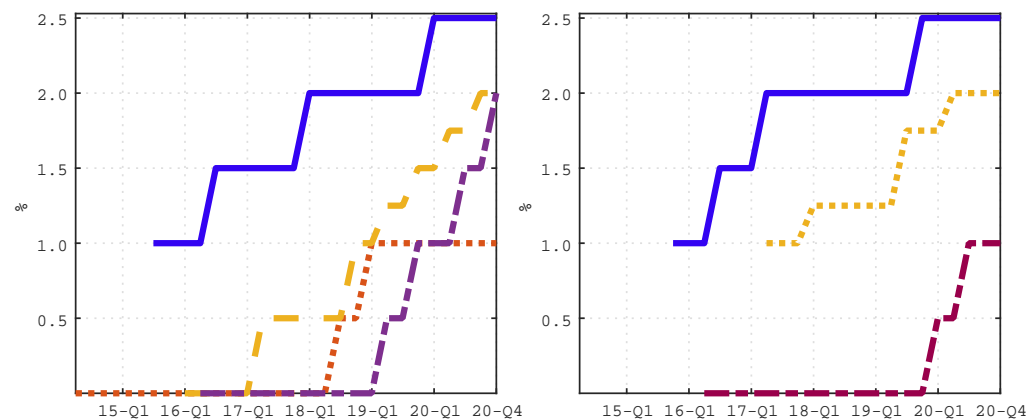

- NOR
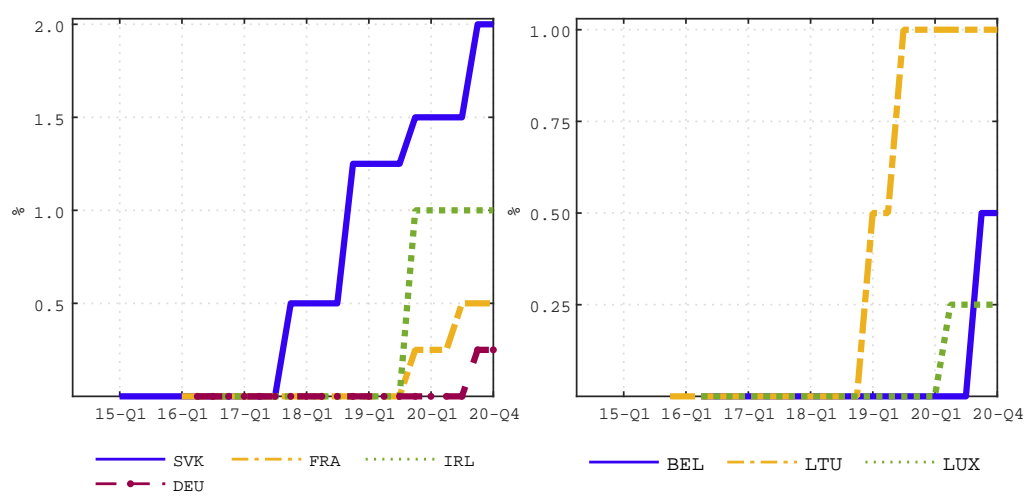

Note: The first two plots represent the regulated level of loan-to-value in EU countries where LTV restrictions have been implemented or announced. The four subsequent plots represent the level of CCyBs in European countries that have implemented or announced the implementation of this instrument.

The countries are Belgium (BEL), Bulgaria (BGR), Cyprus (CYP), Czech Republic (CZE), Germany (DEU), Denmark (DNK), Spain (ESP), Estonia (EST), Finland (FIN), France (FRA), United Kingdom (GBR), Ireland (IRL), Iceland (ISL), Lithuania (LTU), Luxembourg (LUX), Latvia (LVA), Netherlands (NLD), Norway (NOR), Slovakia (SVK) and Sweden (SWE).

Values correspond to announcements as of 6 November 2019.

Source: Alam et al. (2019). 


\section{E Model-consistent output gap and credit-to-GDP gap}

The aim of this appendix is to demonstrate how the output gap and the Basel gap can be derived from the model by applying a Hodrick-Prescott (HP) filter.

Let us start by considering any variable $y_{t}$, which is decomposed into a cyclical component (noted $\widetilde{y_{t}}$ ) and a growth component (noted $x_{t}$ ), such that

$$
y_{t}=\widetilde{y_{t}}+x_{t}
$$

To obtain this decomposition, it is necessary to apply the HP filter programme given by:

$$
\min _{\left\{x_{t}\right\}_{t=1}^{T}} \mathcal{L}_{t}=\sum_{t=1}^{T}\left\{\left(y_{t}-x_{t}\right)^{2}+\lambda_{H P}\left[\left(x_{t+1}-x_{t}\right)-\left(x_{t}-x_{t-1}\right)\right]^{2}\right\},
$$

where $\lambda_{H P}$ penalizes the acceleration of the growth component. The solution of this programme, given by the first-order condition, links the cyclical component to changes in the growth component in adjacent periods as follows:

$$
\frac{\partial \mathcal{L}_{t}}{\partial x_{t}}=0 \Leftrightarrow y_{t} \lambda_{H P} x_{t+2}-4 \lambda_{H P} x_{t+1}+\left(1+6 \lambda_{H P}\right) x_{t}-4 \lambda_{H P} x_{t-1}+\lambda_{H P} x_{t-2}
$$

By denoting the lag operator as $L$, such that $L^{i}\left(y_{t}\right)=y_{t-i}$, and the forward operator as $F$, such that $F^{i}\left(y_{t}\right)=L^{-i}\left(y_{t}\right)=\mathrm{E}_{t}\left(y_{t+i}\right)$, eq. E2 can be written as:

$$
\begin{aligned}
y_{t} & =\left[\lambda_{H P} F^{2}-4 \lambda_{H P} F+\left(1+6 \lambda_{H P}\right)-4 \lambda_{H P} L+\lambda_{H P} L^{2}\right] x_{t} \\
\Leftrightarrow \quad y_{t} & =\left[1+\lambda_{H P}(1-L)^{2}(1-F)^{2}\right] x_{t}
\end{aligned}
$$

By defining $A(L) \equiv 1+\lambda_{H P}(1-L)^{2}(1-F)^{2}$, one can define $y_{t}=A(L) x_{t}$, as well as $x_{t}=$ $[A(L)]^{-1} y_{t}$. Moreover, given that the cyclical component is defined as $\widetilde{y_{t}}=y_{t}-x_{t}=y\left[1-A(L)^{-1}\right]$, the final filtering equation follows:

$$
\widetilde{y_{t}}=\left[\frac{\lambda_{H P}(1-L)^{2}(1-F)^{2}}{1+\lambda_{H P}(1-L)^{2}(1-F)^{2}}\right] y_{t}
$$

which may be written as follows for convenient state-space representation:

$$
\widetilde{y_{t}}+\lambda_{H P}(1-L)^{2}(1-F)^{2} \widetilde{y_{t}}=\lambda_{H P}(1-L)^{2}(1-F)^{2} y_{t}
$$

Interestingly, not only is the resulting gap variable $\widetilde{y_{t}}$ model-consistent, but it also relies on a parsimonious expression (with only 2 leads and 2 lags), which implies a modest expansion of the model's state space.

This approach is used to define the DSGE-HP output gap, the total Basel gap and the HP-specific household and firm credit-to-GDP gaps, with $y_{t}=\left\{Y_{t},\left(\frac{B_{t}}{Y_{t}}\right),\left(\frac{B_{t}^{i}}{Y_{t}}\right)\right\}$ and $\widetilde{y}_{t}=\left\{\widetilde{Y}_{t},\left(\frac{\widetilde{B_{t}}}{Y_{t}}\right),\left(\frac{\widetilde{B_{t}^{i}}}{Y_{t}}\right)\right\}$, respectively, with $i \in\{I, E\}$. See eqs. B43 to B45 in Appendix B for the full expressions. 


\section{F Calibration}

Table F1: Calibration of the structural parameters and shocks

\begin{tabular}{l|l|c}
\hline \hline Parameter & \multicolumn{1}{|c}{ Description } & Value \\
\hline$\beta_{P}$ & Patient households' discount factor & 0.9943 \\
$\beta_{I}$ & Impatient households' discount factor & 0.975 \\
$\beta_{E}$ & Entrepreneurs' discount factor & 0.975 \\
$\phi$ & Inverse of the Frisch elasticity & 0.5 \\
$\varepsilon^{h}$ & Steady state of housing in households' utility function & 0.2 \\
$a^{P}, a^{I}, a^{E}$ & Degree of habit formation in consumption & 0.856 \\
$\alpha$ & Capital share in the production function & 0.25 \\
$\mu$ & Labour income share of patient households & 0.8 \\
$\iota_{p}$ & Indexation of prices to past inflation & 0.16 \\
$\iota_{w}$ & Indexation of nominal wages to past inflation & 0.276 \\
$\delta$ & Depreciation rate of physical capital & 0.025 \\
$\delta^{b}$ & Cost of managing the bank's capital position & 0.084 \\
$\kappa_{w}$ & Cost of adjusting nominal wages & 99.89 \\
$\kappa_{i}$ & Cost of adjusting investment & 10.18 \\
$\kappa_{P}$ & Cost of adjusting good prices & 28.65 \\
$\kappa_{c a r}$ & Cost of adjusting capital-asset ratio & 50.0 \\
$\kappa_{l e v}$ & Cost of adjusting leverage ratio & 7.63 \\
$\kappa_{b E}$ & Cost of adjusting BLR to entrepreneurs & 9.36 \\
$\kappa_{b H}$ & Cost of adjusting BLR to households & 10.09 \\
$\kappa_{d}$ & Cost of adjusting deposit rate & 3.50 \\
$\varepsilon^{l} /\left(\varepsilon^{l}-1\right)$ & Steady-state markup in the labour market & 5.0 \\
$\varepsilon^{y} /\left(\varepsilon^{y}-1\right)$ & Steady-state markup in the goods market & 6.0 \\
$\varepsilon^{b E} /\left(\varepsilon^{b E}-1\right)$ & Steady-state markup on BLR to entrepreneurs & 1.154 \\
$\varepsilon^{b H} /\left(\varepsilon^{b H}-1\right)$ & Steady-state markup on BLR to households & 1.154 \\
$\varepsilon^{d} /\left(\varepsilon^{d}-1\right)$ & Steady-state markdown on deposit rate & 0.593 \\
$\lambda_{H P}$ & Smoothing parameter of HP filter & 1600 \\
$\rho_{h}$ & Persistence of housing preference shock & 0.92 \\
$\sigma_{h}$ & Standard deviation of housing preference shock & 0.066 \\
$\rho_{a}$ & Persistence of technology shock & 0.94 \\
$\sigma_{a}$ & Standard deviation of technology shock & 0.006 \\
$\rho_{K b}$ & Persistence of bank capital shock & 0.81 \\
$\sigma_{K b}$ & Standard deviation of bank capital shock & 0.050 \\
$\rho_{m}$ & Persistence of collateral shock & 0.93 \\
$\sigma_{m}$ & Standard deviation of collateral shock & 0.002 \\
\hline \hline & & \\
\hline
\end{tabular}


Table F2: Baseline calibration of the policy framework

\begin{tabular}{l|l|c}
\hline \hline Parameter & \multicolumn{1}{|c}{ Description } & Value \\
\hline$\omega^{H}$ & Steady-state risk weight on household credit & 0.37 \\
$\rho_{H}$ & Persistence of the risk weight on household credit & 0.94 \\
$\chi_{H}$ & Sensitivity of $\omega^{H}$ to the business cycle & -15 \\
$\omega^{E}$ & Steady-state risk weight on entrepreneur credit & 1.0 \\
$\rho_{E}$ & Persistence of the risk weight on entrepreneur credit & 0.92 \\
$\chi_{E}$ & Sensitivity of $\omega^{E}$ to the business cycle & -10 \\
$v$ & Steady state of capital adequacy ratio & 0.08 \\
$l e v$ & Steady state of leverage ratio & 0.069 \\
$\rho_{v}$ & Smoothing parameter in the capital adequacy ratio rule & 0.99 \\
$\chi_{v}$ & Reaction parameter in capital adequacy ratio rule & {$[0,20]$} \\
$L T V$ & Steady-state LTV ratio for impatient households & 0.7 \\
$\rho_{l t v}^{H}$ & Smoothing parameter in LTV rule for households & 0.99 \\
$\chi_{l t v}^{H}$ & Reaction parameter in LTV rule for households & {$[-20,0]$} \\
$L T V$ & Steady-state LTV ratio for entrepreneurs & 0.8 \\
$\rho_{l t v}^{E}$ & Smoothing parameter in LTV rule for entrepreneurs & 0.99 \\
$\chi_{l t v}^{E}$ & Reaction parameter in LTV rule for entrepreneurs & {$[-20,0]$} \\
$\rho_{r}$ & Smoothing parameter in monetary policy rule & 0.768 \\
$\chi_{\pi}$ & Reaction parameter to inflation in monetary policy rule & {$[1.7,5]$} \\
$\chi_{y}$ & Reaction parameter to output gap in monetary policy rule & {$[0,5]$} \\
\hline \hline
\end{tabular}




\section{G Policy frontiers}

Figure G1: Real side effects of the CCyB: Illustration with policy frontiers
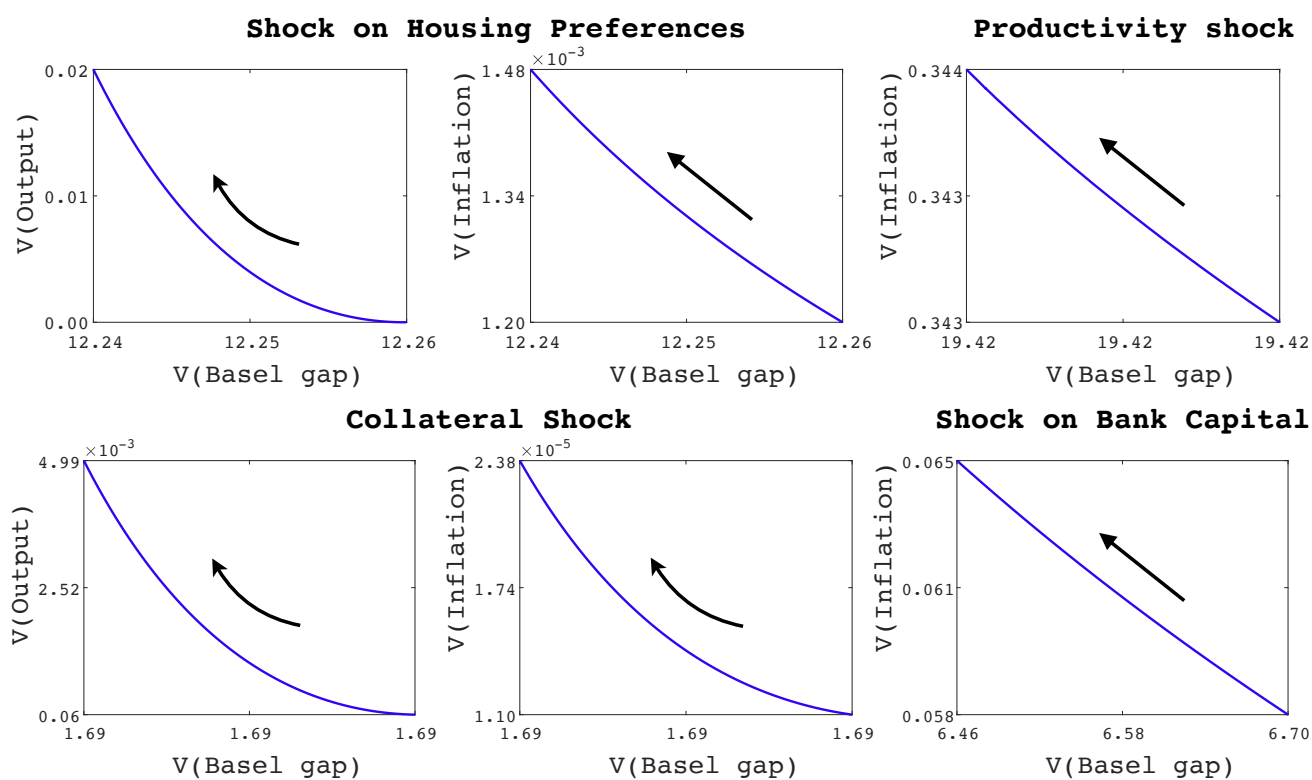

Shock on Bank Capital

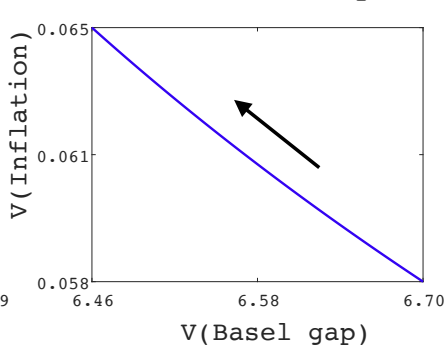

Note: Each plot represents the evolution of the variances of the Basel gap, output and inflation as the loss function of the policymaker, given by

$$
\mathcal{L}=\lambda_{\pi} \sigma_{\pi}^{2}+\lambda_{Y} \sigma_{Y}^{2}+\lambda_{B . g a p} \sigma_{B . g a p}^{2}+\lambda_{C A R} \sigma_{\Delta C A R}^{2}+\lambda_{r} \sigma_{\Delta r}^{2}+\lambda_{H} \sigma_{\Delta L T V^{H}}^{2}+\lambda_{E} \sigma_{\Delta L T V^{E}}^{2},
$$

is minimized with respect to the optimized value of $\chi_{\text {ccyb }}$ in eq. 17 , the capital asset requirement (CAR) rule, subject to the structural model, and conditional on a given shock.

$\sigma_{x}^{2}$, for $x=\left\{\pi, Y, B g a p, \Delta C A R, \Delta r, \Delta L T V^{H}, \Delta L T V^{E}\right\}$ represent the theoretical variances of inflation, output, and the Basel gap, and the theoretical variances of the change in instruments, namely, statecontingent capital asset requirements, the policy rate, and LTV caps for households and entrepreneurs, respectively. $\lambda_{\pi}=1$. and $\lambda_{Y}=0.5$ are the relative weights assigned to the objectives of inflation and output stabilization. $\lambda_{r}=0.1$ and $\lambda_{C A R}=\lambda_{H}=\lambda_{E}=1.0$ are the weights assigned to the volatility of the policy instruments, i.e., the monetary policy rate, CAR, mortgage LTV and corporate LTV, respectively. Finally, $\lambda_{\text {B.gap }}$ is the relative weight assigned to the stabilization of the Basel gap, lying between 0.01 and 1.0 .

The corresponding optimal values of $\chi_{c c y b}$ are consistent with the range of variation considered in Figure 6, while the other parameters in all the policy rules, including the auto-regressive parameters, are set to their baseline values to neutralize the effects of the other policy instruments and to reduce the calculation time.

The arrow in each plot designates the direction in which $\lambda_{B \text {.gap }}$ increases.

On the plots, we denote $\mathrm{V}($ Inflation $) \equiv \sigma_{\pi}^{2}, \mathrm{~V}($ Output $) \equiv \sigma_{Y}^{2}$, and $\mathrm{V}($ Basel gap $) \equiv \sigma_{\text {B.gap }}^{2}$. 
Figure G2: Real side effects of LTV for households: Illustration with policy frontiers
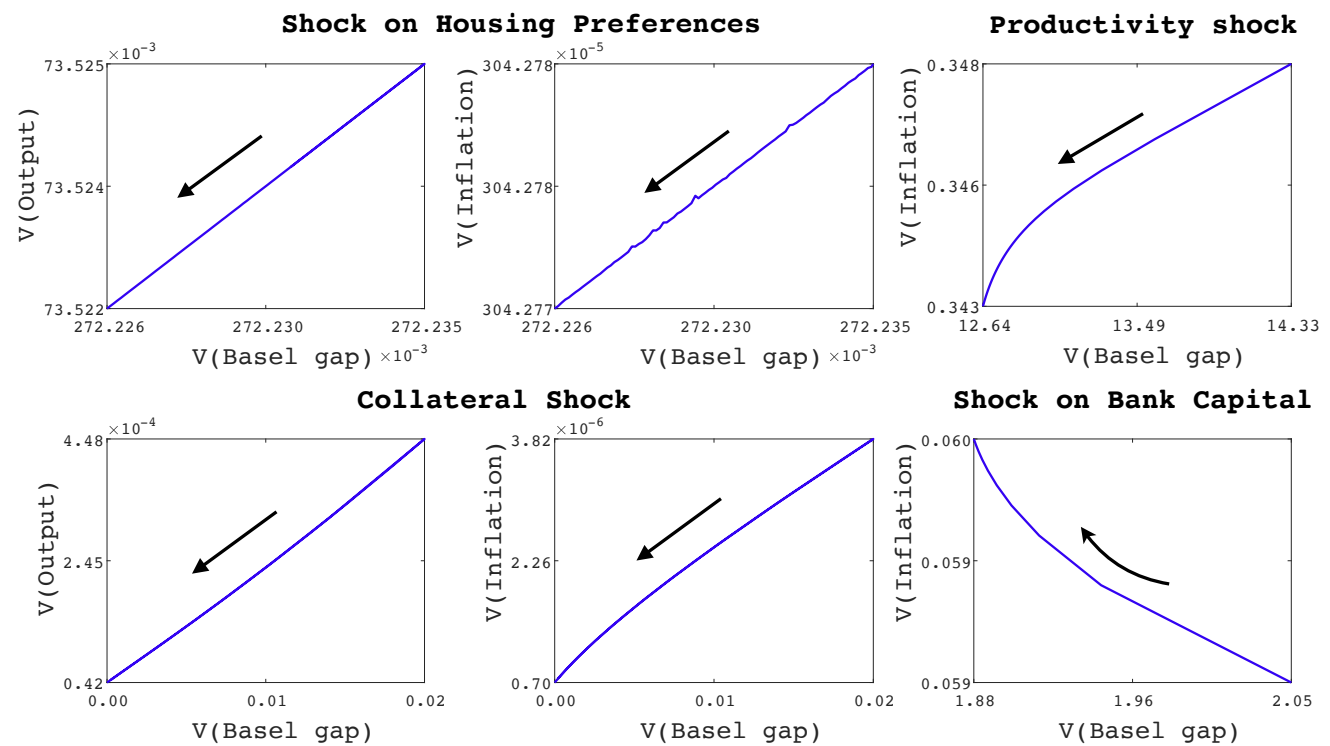

Shock on Bank Capital

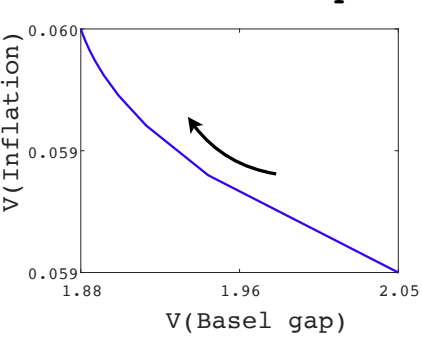

Note: Each plot represents the evolution of the variances of the Basel gap, output and inflation as the loss function of the policymaker, given by eq. G1, is minimized with respect to the optimized value of $\chi_{L T V}^{H}$ in eq. 18, the LTV rule for households, subject to the structural model, and conditional on a given shock.

$\sigma_{x}^{2}, \forall x=\left\{\pi, Y, \operatorname{Bgap}, \Delta C A R, \Delta r, \Delta L T V^{H}, \Delta L T V^{E}\right\}$ represent the theoretical variances of inflation, output, and the Basel gap, and the theoretical variances of the change in instruments, namely, statecontingent capital asset requirements, the policy rate, and LTV caps for households and entrepreneurs, respectively. $\lambda_{\pi}=1.0$ and $\lambda_{Y}=0.05$ are the relative weights assigned to the objectives of inflation and output stabilization, respectively. $\lambda_{r}=0.1$ and $\lambda_{C A R}=\lambda_{H}=\lambda_{E}=1.0$ are the weights assigned to the volatility of the policy instruments, i.e., the monetary policy rate, CAR, mortgage LTV and corporate LTV, respectively. Finally, $\lambda_{B . g a p}$ is the relative weight assigned to the stabilization of the Basel gap. It lies between 0.01 and 1 .

The corresponding optimal values of $\chi_{L T V}^{H}$ are consistent with the range of variation considered in Figure 7, while the other parameters in all the policy rules, including the autoregressive parameters, are set to their baseline values to neutralize the effects of the other policy instruments and to reduce the calculation time.

The arrow in each plot designates the direction in which $\lambda_{B . g a p}$ increases.

$\mathrm{V}($ Inflation $) \equiv \sigma_{\pi}^{2}, \mathrm{~V}($ Output $) \equiv \sigma_{Y}^{2}$, and $\mathrm{V}($ Basel gap $) \equiv \sigma_{B . g a p}^{2}$

Note that the last plot in the second row represents the only clear-cut trade-off occurring while the LTV for households is implemented. 
Figure G3: Real side effects of LTV for firms: Illustration with policy frontiers
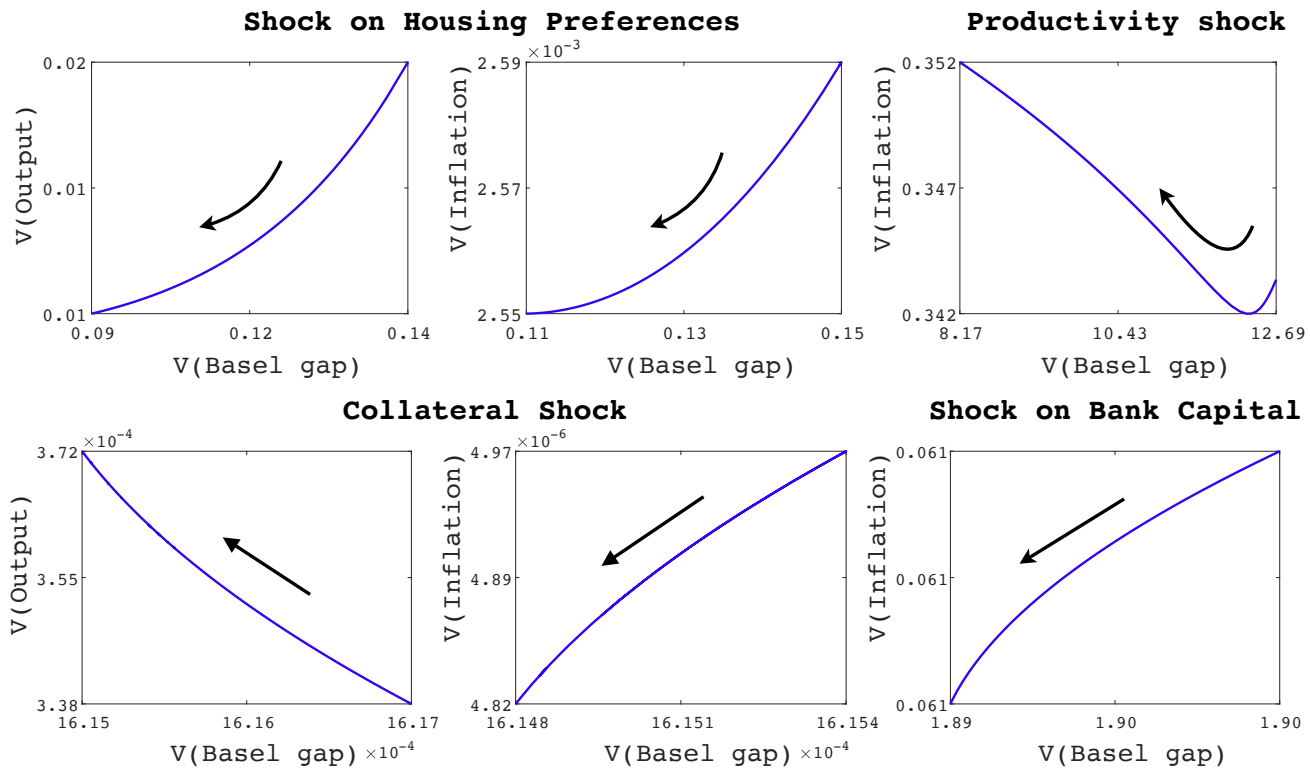

Shock on Bank Capital

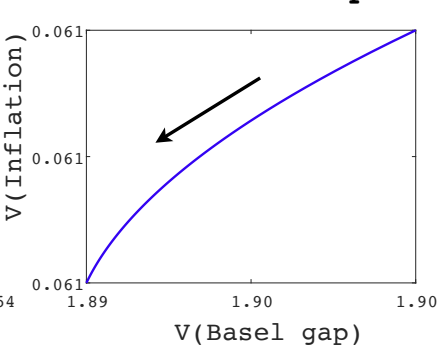

Note: Each plot represents the evolution of the variances of the Basel gap, output and inflation as the loss function of the policymaker, given by eq. G1, is minimized with respect to the optimized value of $\chi_{L T V}^{E}$ in eq. 18, the LTV rule for entrepreneurs, subject to the structural model, and conditional on a given shock.

$\sigma_{x}^{2}, \forall x=\left\{\pi, Y\right.$, Bgap $\left., \Delta C A R, \Delta r, \Delta L T V^{H}, \Delta L T V^{E}\right\}$ represent the theoretical variances of inflation, output, and the Basel gap, and the theoretical variances of the change in instruments, namely, statecontingent capital asset requirements, the policy rate, and LTV caps for households and entrepreneurs, respectively. $\lambda_{\pi}=1.0$ and $\lambda_{Y}=0.04$ are the relative weights assigned to the objectives of inflation and output stabilization, respectively. $\lambda_{r}=0.1$ and $\lambda_{C A R}=\lambda_{H}=\lambda_{E}=1.0$ are the weights assigned to the volatility of the policy instruments, i.e., the monetary policy rate, CAR, mortgage LTV and corporate LTV, respectively. Finally, $\lambda_{\text {B.gap }}$ is the relative weight assigned to the stabilization of the Basel gap. It lies between 0.01 and 1 . The corresponding optimal values of $\chi_{L T V}^{E}$ are consistent with the range of variation considered in Figure 8, while the other parameters in all the policy rules, including the auto-regressive parameters, are set to their baseline values to neutralize the effects of the other policy instruments and to reduce the calculation time.

The arrow in each plot designates the direction in which $\lambda_{B . g a p}$ increases.

On the plots, we denote $\mathrm{V}($ Inflation $) \equiv \sigma_{\pi}^{2}, \mathrm{~V}($ Output $) \equiv \sigma_{Y}^{2}$, and $\mathrm{V}($ Basel gap $) \equiv \sigma_{\text {B.gap }}^{2}$. 
Figure G4: Financial side effects of monetary policy: Illustration with policy frontiers
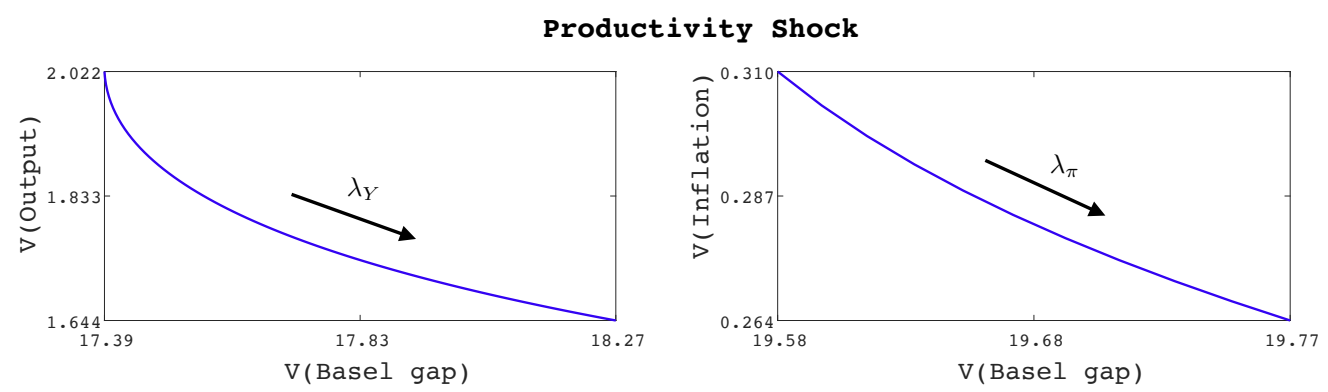

Shock on Housing Preferences
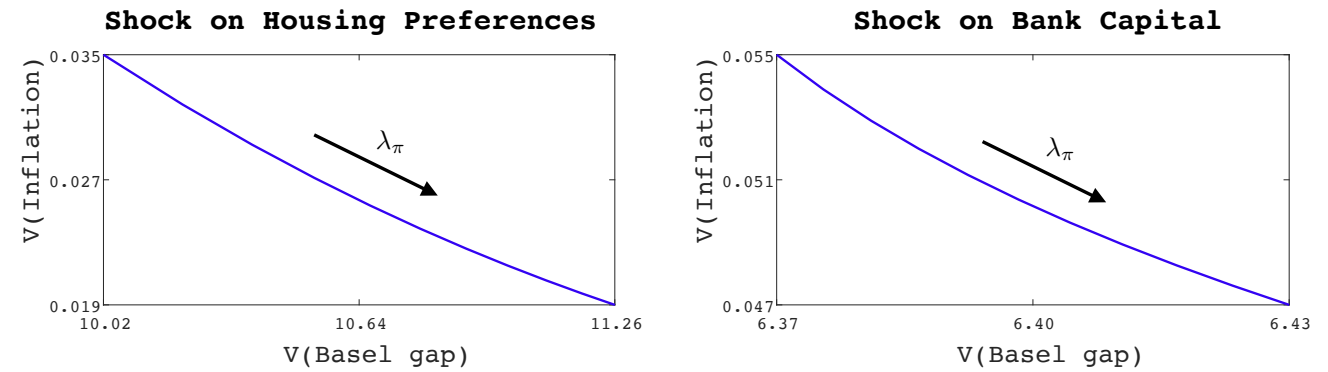

Note: Each plot represents the evolution of the variances of the Basel gap, output and inflation as the loss function of the policymaker, given by eq. G1, is minimized with respect to the optimized value of $\chi_{\pi}$ or $\chi_{y}$ in eq. 19, the monetary policy rule, subject to the structural model, and conditional on a given shock.

$\sigma_{x}^{2}, \forall x=\left\{\pi, Y\right.$, Bgap $\left., \Delta C A R, \Delta r, \Delta L T V^{H}, \Delta L T V^{E}\right\}$ represent the theoretical variances of inflation, output, and the Basel gap, and the theoretical variances of the change in instruments, namely, statecontingent capital asset requirements, the policy rate, and LTV caps for households and entrepreneurs, respectively. $\lambda_{B . g a p}=0.1$ is the relative weight assigned to the stabilization of the Basel gap. $\lambda_{r}=0.1$ and $\lambda_{C A R}=\lambda_{H}=\lambda_{E}=1.0$ are the weights assigned to the volatility of the policy instruments, i.e., the monetary policy rate, CAR, mortgage LTV and corporate LTV, respectively. $\lambda_{Y}$ is the relative weight assigned to the objective of output stabilization. It is equal to 0.5 but varies between $[0.2,1]$ in the first plot. $\lambda_{\pi}$ is the relative weight assigned to the objective of inflation stabilization. It is equal to 1.0 as $\lambda_{Y}$ varies in the case of a productivity shock (first plot), while it lies between 1.0 and 2.0 in the second plot. The corresponding optimal values of $\chi_{\pi}$ and $\chi_{Y}$ are consistent with the ranges of variation considered in Figure 9, while the other parameters in all the policy rules, including the auto-regressive parameters, are set to their baseline values to neutralize the effects of the other policy instruments and to reduce the calculation time.

The arrow in each plot designates the direction in which $\lambda_{\pi}$ or $\lambda_{Y}$ increases.

On the plots, we denote $\mathrm{V}($ Inflation $) \equiv \sigma_{\pi}^{2}, \mathrm{~V}($ Output $) \equiv \sigma_{Y}^{2}$, and $\mathrm{V}($ Basel gap $) \equiv \sigma_{\text {B.gap }}^{2}$. 